\title{
Geodynamically Consistent Seismic Velocity Predictions at the Base of the Mantle
}

\author{
I. Sidorin and Michael Gurnis \\ Seismological Laboratory, California Institute of Technology
}

\begin{abstract}
A model of thermoelastic properties for a chemically homogeneous adiabatic lower mantle is calculated. Constraints provided by this model are used in convection models to study dynamics of a chemically distinct layer at the bottom of the mantle. We find that the layer must be at least $2 \%$ denser than the overlying mantle to survive for a geologically significant period of time. Realistic decrease with depth of the thermal expansivity increases layer stability but is unable to prevent it from entrainment. Seismic velocities are computed for an assumed composition by applying the thermal and compositional perturbations obtained in convection simulations to the adiabatic values. The predicted velocity jump at the top of the chemical layer is closer to the CMB in the cold regions than in the hot. The elevation of the discontinuity above CMB in the cold regions decreases with increasing thermal expansivity and increases with increasing density contrast, while in the hot regions we find that the opposite is true. If the density contrast is small, the layer may vanish under downwellings. However, whenever the layer is present in the downwelling regions, it also exists under the upwellings. For a $4 \%$ density contrast and realistic values of expansivity, we find that the layer must be more than $400 \mathrm{~km}$ thick on average to be consistent with the seismically observed depth of the discontinuity. A simple chemical layer cannot be used to interpret the D" discontinuity: the required change in composition is large and must be complex, since enrichment in any single mineral probably cannot provide the required impedance contrast. A simple chemical layer cannot explain the spatial intermittance of the discontinuity.
\end{abstract}

\section{INTRODUCTION}

The D" region at the base of the mantle has been the focus of considerable seismological, geochemical and geodynamical study (see the review by Loper and Lay, [1995]). Although our knowledge of the region has dramatically improved, we still lack a comprehensive understanding of the processes responsible for the structures at the bottom of the mantle. Moreover, we lack

The Core-Mantle Boundary Region

Geodynamics 28

Copyright 1998 by the American Geophysical Union. a unified theory which is needed to reconcile diverse observations.

Some of the most detailed and relevant observations concerning the $\mathrm{D}$ " region come from seismology. Most significant, perhaps, are the results of high resolution tomography inversions [Grand, 1994; van der Hilst et $a l ., 1997]$ which show that distinct seismically fast anomalies can be connected to subducted slabs. Though differing in details, the recent tomographic models agree at large scales at the bottom of the mantle. The most striking features of both models are well defined fast velocity anomalies under the Americas and Southern Asia which can be linked to the subducted Farallon and Tethys plates [Grand et al., 1997]. 
Another source of information on $\mathrm{D}$ " is the analysis of the travel times of various core phases (including traversing, reflected and diffracted phases). These studies provide more localized information on the bottom of the mantle. Significant findings include a triplication caused by an apparent $2-3 \%$ velocity jump a few hundred kilometers above the CMB [Lay and Helmberger, 1983] and an ultra-low velocity zone (ULVZ) at the bottom 40 kilometers or less of the mantle [Garnero and Helmberger, 1995; Garnero and Helmberger, 1996]. The most likely cause of the ULVZ is partial melting [Williams and Garnero, 1996], but other interpretations, such as chemical anomalies cannot be ruled out. While the model of Lay and Helmberger [1983] is a viable interpretation of the observed triplication at the top of D", an alternative model has been suggested by Ding [1997] who demonstrated that the observed triplication can be explained by a smaller velocity jump (1\%) than previously suggested (2-3\%), provided that the vertical gradient of velocity is sufficiently high as may exist atop an old cold slab with a diffuse boundary layer.

The complexity of the region, its remoteness from the surface, and its ultimate importance in the global dynamics of the Earth call for an interdisciplinary approach to its exploration. Several such studies have been undertaken. Christensen and Hofmann [1994] studied mixing and transport in a thermo-chemical model of convection and predicted isotopic systematics of mantle derived basalts. Forte and Peltier [1989] compared seismically inferred CMB topography with that produced by a global flow model using buoyancy constrained by seismic tomography. Several studies attempted to predict temperature or density variations in the mantle from tomographic models [e.g., Hager et $a l ., 1985 ;$ Yuen et al., 1993] or seismic velocities from dynamic models [e.g., Davies and Gurnis, 1986]. However, all previous studies generally use simple scalings between temperature and seismic velocity while a comprehensive interrelation between the dynamic modeling and mantle composition and thermoelastic properties is required.

It is obvious that the increasing resolution of tomography, more sophisticated dynamical models, and rapidly developing techniques in mineral physics experiments which provide elastic properties at higher pressures and temperatures, require a systematic approach to the problem. Such a systematic approach should allow us to close the gap between seismological inversions and dynamic models.
In this work we address the problem of the dynamics of the D" region and develop tools for testing numerical convection models against seismological observations by predicting seismic velocities from convection models. We first study the dynamics of a chemically distinct layer at the bottom of the mantle and explore the conditions under which such layer would survive for extended periods of time. Then we determine the properties of this layer which are consistent with fundamental seismological observations of the CMB region.

To make the dynamic simulation and inferred seismic velocities consistent, a coherent adiabatic reference model of thermoelastic parameters as a function of depth is required for the whole mantle. Since the focus of this study is the bottom of the mantle, we start by computing an adiabatic model for a chemically homogeneous lower mantle, using currently existing mineral physics data and geochemical constraints. Where necessary, the upper mantle parameters can be evaluated by interpolating between the lower mantle and surface values.

A convection model is then formulated with a bottom layer of specified physical properties. The convection in the mantle is then simulated numerically using parameters consistent with the adiabatic $1 \mathrm{D}$ model and the corresponding properties (such as density) of the bottom layer. The temperature field and the spatial distribution of the distinct material, obtained from the simulation, are then used to adjust the adiabatic elastic parameters to account for the effects of non-adiabaticity. This approach provides a dynamically consistent twodimensional field of seismic velocities. Thus, the calculated seismic velocities are closely linked to the geodynamic model through the adiabatic 1D parameters and properties of the distinct material.

\section{ADIABATIC MODEL FOR CHEMICALLY HOMOGENEOUS LOWER MANTLE}

The approach we used to calculate the adiabatic model for a chemically homogeneous lower mantle is similar to that of Zhao and Anderson [1994]. A (Mg,Fe) $\mathrm{SiO}_{3}$ perovskite - $(\mathrm{Mg}, \mathrm{Fe}) \mathrm{O}$ magnesiowüstite lower mantle composition is assumed with given molar partitioning coefficient $\chi_{\mathrm{Pv}}=\mathrm{Pv} /(\mathrm{Pv}+\mathrm{Mw})$ and a molar fraction of iron $\chi_{\mathrm{Fe}}=\mathrm{Fe} /(\mathrm{Fe}+\mathrm{Mg})$. The values of the adiabatic bulk modulus, $K_{S}$, rigidity, $G$, and density, $\rho$, at a given foot temperature, $T_{f}$, of the adiabat (i.e. temperature at depth $z=0$ ), are calculated separately 
for $(\mathrm{Mg}, \mathrm{Fe}) \mathrm{SiO}_{3}$ and $(\mathrm{Mg}, \mathrm{Fe}) \mathrm{O}$ using equations [Burdick and Anderson, 1975]:

$$
\begin{aligned}
K_{S}\left(P_{0}, T_{f}\right) & =K_{S_{0}} \exp \left\{-\int_{T_{s}}^{T_{f}} \alpha(T) \bar{\delta}_{S} d T\right\} \\
G\left(P_{0}, T_{f}\right) & =G_{0} \exp \left\{-\int_{T_{s}}^{T_{f}} \alpha(T) \bar{\Gamma} d T\right\} \\
\rho\left(P_{0}, T_{f}\right) & =\rho_{0} \exp \left\{-\int_{T_{s}}^{T_{f}} \alpha(T) d T\right\}
\end{aligned}
$$

where $T_{s}=300 \mathrm{~K}$ is the surface temperature, $P_{0}=$ 0 is the surface pressure, $K_{S_{0}}=K_{S}\left(P_{0}, T_{s}\right), G_{0}=$ $G\left(P_{0}, T_{s}\right)$ and $\rho_{0}=\rho\left(P_{0}, T_{s}\right)$ are the ambient adiabatic bulk modulus, rigidity and density, respectively, $\alpha(T) \equiv 1 / V(\partial V / \partial T)_{P}$ is the coefficient of thermal expansion at $P=0, \bar{\delta}_{S} \equiv\left(\partial \ln K_{S} / \partial \ln \rho\right)_{P}$ and $\bar{\Gamma} \equiv$ $(\partial \ln G / \partial \ln \rho)_{P}$ are average dimensionless anharmonic parameters at $P=0$ (taken as a mean value of the corresponding ambient and high temperature parameters).

The major difference between our calculations and the study of Zhao and Anderson [1994] is in the approach to the pressure and temperature dependence of the coefficient of thermal expansion, $\alpha$. The coefficient of thermal expansion has a significant influence on both the dynamics of convection [Yuen et al., 1991] and the seismic velocity calculation and is the major parameter linking the convection simulation and seismic velocity prediction in our study. This is why an accurate analysis of this important property as a function of pressure, temperature and composition is required.

The values of $\alpha$ for magnesiowüstite reported by various authors [e.g., Chopelas, 1996; Chopelas and Boehler, 1992; Duffy and Ahrens, 1993; Isaak et al., 1989; Isaak et al., 1990; Suzuki, 1975] seem to agree rather well with each other. Though the current state of the experimental techniques is not able to provide accurate measurements at simultaneous high pressures and temperatures appropriate for the bottom of the mantle, the values at intermediate pressures and temperatures can be extrapolated to the required conditions with a certain degree of uncertainty. Fortunately, there seems to be general agreement on the first-order temperature and pressure dependence of $\alpha$ for $(\mathrm{Mg}, \mathrm{Fe}) \mathrm{O}$ [Anderson et al., 1992; Chopelas and Boehler, 1992]. For temperature dependence of the coefficient of thermal expansion of magnesiowüstite at $P=0$ in equations (1)-(3) we use the data from Isaak et al. [1989].

However, the database of experimental measurements of $\alpha$ for silicate perovskite, $(\mathrm{Mg}, \mathrm{Fe}) \mathrm{SiO}_{3}$, is sparse and inconsistent even at ambient conditions. An analysis of various reports shows that the range of reported values seem to have a bimodal nature, clustering around low values of about $1.7 \times 10^{-5} \mathrm{~K}^{-1}$ [Wang et al., 1994; Chopelas, 1996; Stacey, 1996] and high values about $4.0 \times 10^{-5} \mathrm{~K}^{-1}$ [Knittle et al., 1986; Mao et al., 1991; Patel et al., 1996].

In this study, the low values of $\alpha$ for $(\mathrm{Mg}, \mathrm{Fe}) \mathrm{SiO}_{3}$ are favored for the following reasons. First, such values were supported by different experimental techniques. The values of the coefficient of thermal expansion obtained in large volume press experiments [Funamori and Yagi, 1993; Wang et al., 1994; Utsumi et al., 1995] agree reasonably well with each other and the results of Raman spectroscopy measurements [Chopelas, 1996]. Secondly, such choice is supported by a statistical analysis of existing $P-V-T$ data [Jackson and Rigden, 1996] and theoretical thermodynamic considerations [Anderson et al., 1995; Stacey, 1996]. Besides, it has been suggested [Wang et al., 1994] that the early measurements of expansivity of $(\mathrm{Mg}, \mathrm{Fe}) \mathrm{SiO}_{3}$ may have been made outside the stability field and so may not be correct. Taking the huge uncertainty in measured values, we follow the approach of Anderson et al. [1995] and compute $\alpha$ from thermoelastic parameters [Anderson and Masuda, 1994] rather than use it as an input parameter. So the choice between the low and high values of $\alpha$ is, in fact, the choice between the values of the corresponding thermoelastic parameters.

The computation begins with the Suzuki et al. [1979] equation:

$$
\frac{\Delta V}{V_{0}}=\frac{\left[1+2 \tilde{k}-\left(1-\frac{4 \tilde{k} E_{T H}(\Theta / T)}{Q}\right)^{1 / 2}\right]}{2 \tilde{k} a_{v}}-1,
$$

where $V_{0}$ is the molar volume; $\tilde{k}=(1 / 2)\left(K_{T}^{\prime}-1\right)$, where $K_{T}^{\prime}=\partial K_{T} / \partial P$ is the pressure derivative of the bulk modulus; $a_{v}=V\left(T_{s}\right) / V(0) ; Q=K_{T_{0}} V_{0} / \gamma_{0}$, where $K_{T_{0}}$ is the ambient isothermal bulk modulus, $\gamma_{0}$ is the ambient pressure Grüneisen ratio; $E_{T H}(\Theta / T)$ is the Debye energy and $\Theta$ is the Debye temperature. The temperature dependence of the ambient pressure coefficient of thermal expansion, $\alpha\left(P_{0}, T\right)$ is then obtained as a temperature derivative of $(4)$.

After the values of $K_{S}, G$, and $\rho$ at temperature $T_{f}$ are known, their high pressure values can be calculated using the third-order Birch-Murnaghan equation of state [Birch, 1952]:

$$
P=3 K_{S}\left(P_{0}, T_{f}\right) f(1+2 f)^{5 / 2}\left(1-\frac{3}{2}\left(4-K_{S}^{\prime}\right) f\right),
$$


where $f=\frac{1}{2}\left[\rho(P, T) / \rho\left(P_{0}, T_{f}\right)\right]^{2 / 3}-1$ is the finite strain. Then the elastic parameters of the adiabatically compressed material can be calculated as follows [Sammis et al., 1970; Davies and Dziewonski, 1975]:

$$
\begin{aligned}
K_{S}(P, T)= & K_{S}\left(P_{0}, T_{f}\right)(1+2 f)^{5 / 2}[1+ \\
& \left.\left(3 K_{S}^{\prime}-5\right) f\right] \\
G(P, T)= & G\left(P_{0}, T_{f}\right)(1+2 f)^{5 / 2}\{1+ \\
& {\left.\left[3 G^{\prime} K_{S}\left(P_{0}, T_{f}\right) / G\left(P_{0}, T_{f}\right)-5\right] f\right\}(7) } \\
\rho(P, T)= & \rho\left(P_{0}, T_{f}\right)(1+2 f)^{3 / 2} .
\end{aligned}
$$

The elastic properties of the composite material are calculated by taking a Reuss-Voigt-Hill (RVH) average of the corresponding values for perovskite and magnesiowüstite:

$$
M=\left\{\frac{M_{\mathrm{Pv}} M_{\mathrm{Mw}}\left[\chi_{\mathrm{Pv}}^{v o l} \cdot M_{\mathrm{Pv}}+\left(1-\chi_{\mathrm{Pv}}^{v o l .}\right) M_{\mathrm{Mw}}\right]}{\chi_{\mathrm{Pv}}^{v o l} \cdot M_{\mathrm{Mw}}+\left(1-\chi_{\mathrm{Pv}}^{\text {vol. }}\right) M_{\mathrm{Pv}}}\right\}^{1 / 2},
$$

where $M$ is either $K_{S}, G$ or $\rho$ and $\chi_{\mathrm{Pv}}^{\text {vol. }}$ is the volume fraction of perovskite that can be calculated from the molar fraction $\chi_{\mathrm{Pv}}$.

The adiabatic temperature in the mantle is calculated using equation

$$
\frac{d T}{d z}=\frac{T \gamma \rho g}{K_{S}},
$$

where $\gamma$ is the Grüneisen parameter. It is generally accepted that the values of $\gamma$ are not very sensitive to temperature above $\Theta[D$. L. Anderson, 1988; Anderson et al., 1996]. The effect of compression on $\gamma$ is given by [Anderson et al., 1993]

$$
\gamma=\gamma_{0} \eta^{q}
$$

where $\eta=\rho\left(P_{0}, T_{f}\right) / \rho(P, T)$ and $\gamma_{0}$ is the value at $\eta=$ 1. The dimensionless parameter $q$ has values close to 1 for most minerals but is itself a function of pressure and temperature.

We separately calculate the Grüneisen parameters for perovskite and magnesiowüstite and then take the RVH average to represent the Grüneisen parameter of the compound material which is used in the equation for temperature (9).

To calculate the coefficient of thermal expansion along the mantle adiabat, the calculated isobars $\alpha\left(P_{0}, T\right)$ must first be converted to isochores $\alpha(\eta=1, T)$. This is done by integrating the identity

$$
\left(\frac{\partial \alpha}{\partial T}\right)_{V}=\left(\frac{\partial \alpha}{\partial T}\right)_{P}-\bar{\delta}_{T} \alpha^{2}
$$

obtained by Anderson and Masuda [1994]. The Anderson - Grüneisen parameter, $\delta_{T}$, varies with temperature below the Debye temperature [e.g., Isaak et al., 1990], so we use the average value, $\bar{\delta}_{T}$, of the ambient and high temperature values in the equation above. After that the coefficient of thermal expansion at a given temperature, $T$, and compression, $\eta$, can be calculated using the following equation, obtained by Anderson et al. [1992]:

$$
\alpha(T, \eta)=\alpha(T, \eta=1) \exp \left[-\frac{\delta_{T_{0}}}{k}\left(1-\eta^{k}\right)\right],
$$

where $\delta_{T_{0}}$ is the high-temperature value of the Anderson - Grüneisen parameter at zero pressure, and $k$ is a dimensionless thermoelastic parameter controlling the dependence of $\delta_{T}$ on compression [Anderson and Issak, 1993]:

$$
\delta_{T}=\delta_{T_{0}} \eta^{k}
$$

We use equations (12) and (13) to calculate $\alpha$ and $\delta_{T}$, respectively, along the adiabat. The calculations are performed separately for perovskite and magnesiowüstite and a RVH average is taken to represent the lower mantle values.

The pressure dependence of the adiabatic Anderson - Grüneisen parameter, $\delta_{S} \equiv\left(\partial \ln K_{S} / \partial \ln \rho\right)_{P}$, has received significant attention recently. This parameter controls the sensitivity of the adiabatic bulk modulus, $K_{S}$, to temperature and is essential in evaluation of the temperature dependence of the compressional seismic velocity. The discussion on the matter was stimulated by an observation of apparent inconsistency of seismic tomography results with the mineral physics data that was first noted by $D$. L. Anderson [1987] from the analysis of seismic velocities variation in tomographic models. The ratio of the relative shear velocity lateral variations to the compressional velocity variations, $\left(\partial \ln V_{S} / \partial \ln V_{P}\right)_{P}$, calculated from seismic tomography models, is about a factor of 2 larger than the estimates from zero-pressure mineral physics data, and the separate analysis of $P$ and $S$ velocity variations gives $\Gamma$ values at the bottom of the mantle similar to the zero-pressure values $(\approx 5.8)$, while requires significantly lower values of $\delta_{S}(\approx 1.8)$ than the zero-pressure measurements $(\approx 4.0)[D$. L. Anderson, 1987].

The problem of $\delta_{S}$ pressure dependence was later addressed by Agnon and Bukowinski [1990] and Isaak et al. [1992]. Both studies provided further support for the relative insensitivity of $\Gamma$ to pressure and a substantial decrease in $\delta_{S}$.

Anderson [1967] showed an empirical relationship

$$
\delta_{S} \approx \delta_{T}-\gamma,
$$

valid for most minerals above the Debye temperature. From the analysis of the high temperature data on $\mathrm{NaCl}$ 
and $\mathrm{KCl}$, Yamamoto et al. [1987] suggested that the following form of the relationship is more appropriate:

$$
\delta_{S} \approx \delta_{T}-1.4 \gamma
$$

We use the relationship (15) to calculate $\delta_{S}$ along the adiabat. Parameter $\Gamma$ is assumed to be constant along the adiabat and equal to 5.25 , consistent with hightemperature values for $\mathrm{MgO}$ [Isaak et al., 1989; Isaak et al., 1992].

Following the described procedure, we calculate adiabatic profiles of $K_{S}, G, \rho, T, \alpha, \gamma, \delta_{T}$, and $\delta_{S}$ for a homogeneous lower mantle. Significant tradeoffs exist between the composition, foot temperature of the adiabat, $T_{f}$, and zero-pressure values of the coefficient of thermal expansion, $\alpha$ [Bukowinski and Wolf, 1990; Hemley et al., 1992; Stixrude et al., 1992; Zhao and Anderson, 1994; Stacey, 1996]. The coefficient of thermal expansion, in turn, depends on several thermodynamic parameters, of which the most important are the Grüneisen ratio, $\gamma$, and the Anderson - Grüneisen parameter, $\delta_{T}[$ Anderson et al., 1995; Stacey, 1996].

Parameters $\chi_{\mathrm{Pv}}, \chi_{\mathrm{Fe}}, T_{f}$ were systematically varied in the limits $0.5-1.0,0.08-0.12$ and $1400-2100 \mathrm{~K}$, respectively, in search for the best fit to PREM in the $800-2600 \mathrm{~km}$ depth range. The top and bottom regions of the lower mantle were excluded because the effects of non-adiabaticity may be significant [e.g., Butler and Anderson, 1978]. The resulting preferred values are $\chi_{\mathrm{Pv}}=0.55, \chi_{\mathrm{Fe}}=0.11$ and $T_{f}=1750 \mathrm{~K}$, which are in agreement with the results of Stacey [1996]. However, this solution is obviously non-unique due to the existing tradeoffs and significant uncertainties in the values of input mineral physical properties and wide bounds of geochemical constraints. The corresponding profiles of density, $\rho$, and elastic moduli, $K_{S}$ and $G$, are given in Figure 1 and the calculated seismic velocities

$$
V_{P}=\sqrt{\frac{K_{S}+\frac{4}{3} G}{\rho}}
$$

and

$$
V_{S}=\sqrt{\frac{G}{\rho}}
$$

are given in Figure 2. The modeling results $\left(\rho, K_{S}\right.$ and $G$ ) have systematically steeper slopes than PREM. Though this may be a drawback of the low-order equation of state, it does not necessarily imply that the calculated along an adiabat thermoelastic parameters are systematically wrong, since weakly super-adiabatic radial gradients of temperature cannot be ruled out for the lower mantle [Bukowinski and Wolf, 1990].
Several assumptions were used in the calculations. First, all parameters involved, except $\rho$ and $G$, are probably not very sensitive to iron content [Mao et al., 1991; Wang et al., 1994]. So in most cases we used the properties of the $\mathrm{Mg}$ end members for both $(\mathrm{Mg}, \mathrm{Fe}) \mathrm{O}$ and $(\mathrm{Mg}, \mathrm{Fe}) \mathrm{SiO}_{3}$ (Table 1). Second, we assumed non-equal partitioning of iron between magnesiowüstite and perovskite, consistent with the study of Kesson and Fitz Gerald [1992]. The iron partitioning coefficients for $(\mathrm{Mg}, \mathrm{Fe}) \mathrm{SiO}_{3}$ and $(\mathrm{Mg}, \mathrm{Fe}) \mathrm{O}$, respectively, were taken as
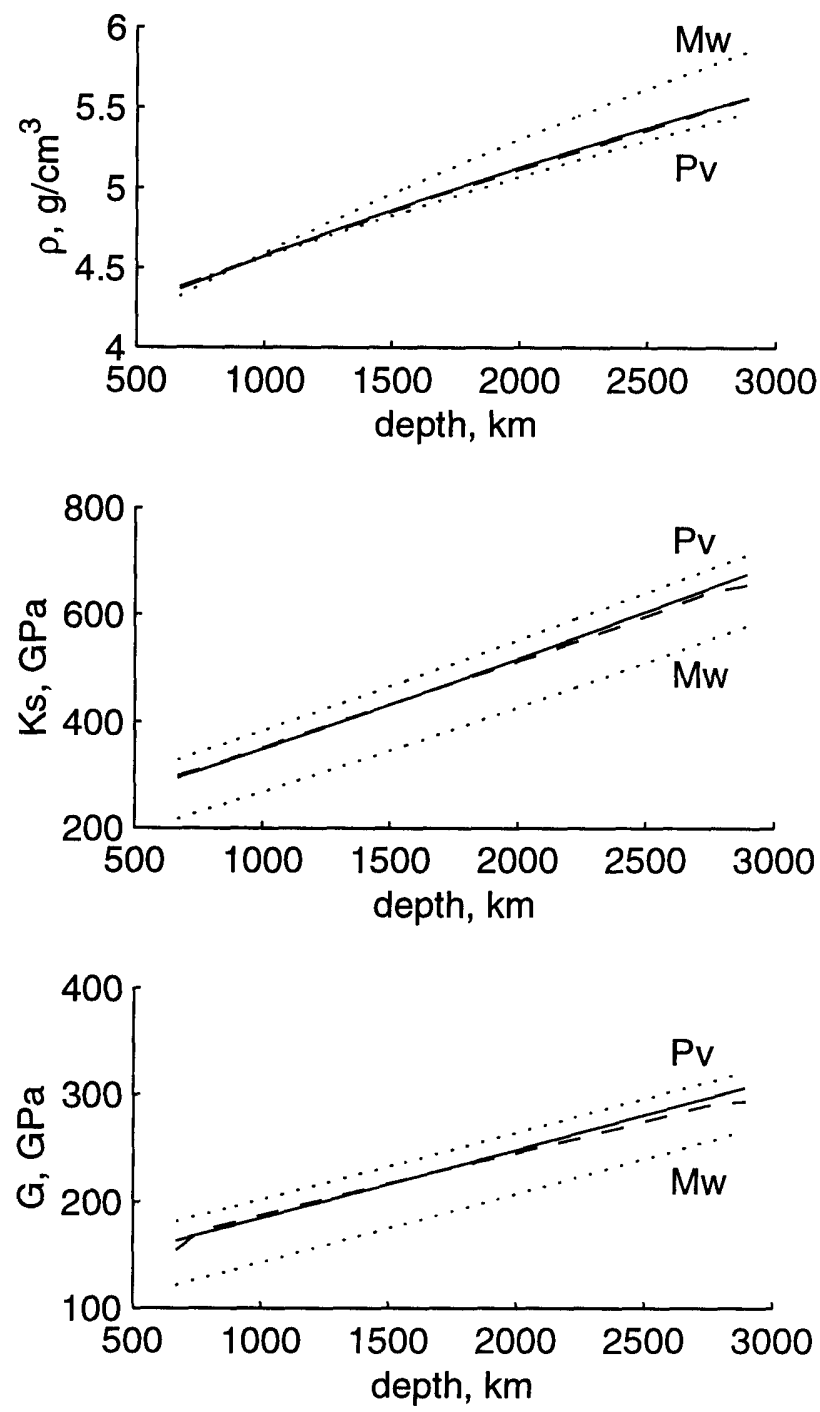

Figure 1. Elastic moduli and density calculated along a mantle adiabat. Dotted lines give values for magnesiowüstite and silicate perovskite; solid lines represent the RVH average values; dashed lines indicate PREM values for reference. 

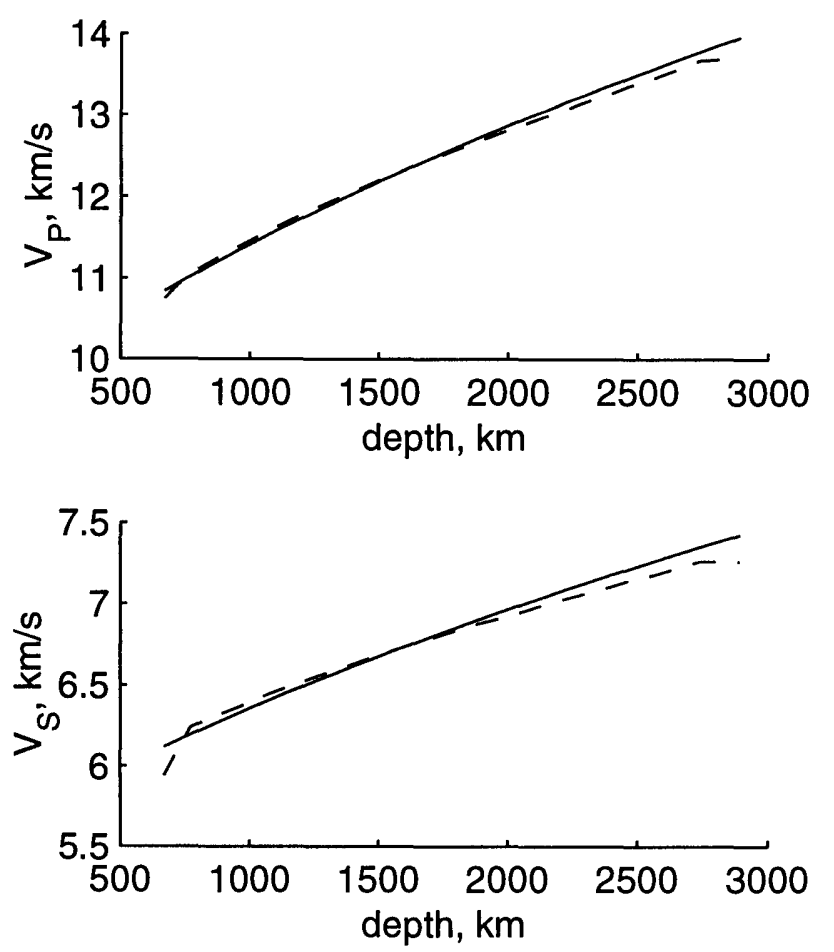

Figure 2. Seismic velocities calculated along a mantle adiabat. Solid lines represent the RVH average values; dashed lines indicate PREM values for reference.

$\chi_{\mathrm{Fe}}^{\mathrm{Pv}}=0.07$ and $\chi_{\mathrm{Fe}}^{\mathrm{Mw}}=1.727 \chi_{\mathrm{Fe}}-0.016$ according to Figure 2 of Kesson and Fitz Gerald [1992].

We neglected the possible effect of the presence of high-pressure phases of $\mathrm{Al}$ and Ca-bearing minerals. These are expected to be in small amounts and in perovskite structure with a minor effect on the properties of the lower mantle [e.g., Jeanloz and Knittle, 1986; Zhao and Anderson, 1994].

The isothermal bulk modulus, $K_{T_{0}}$, in equation (4) was calculated from the adiabatic bulk modulus:

$$
K_{T}=K_{S} /(1+\alpha \gamma T)
$$

and it was assumed that $K_{T}^{\prime} \approx K_{S}^{\prime}[D . L$. Anderson, 1987; Isaak, 1993].

When calculating the pressure dependence of (10) and (13), we took into account the pressure and temperature effects on the values of parameter $q$ [Anderson et al., 1993] and temperature effect on the values of parameter $k$ [Anderson et al., 1992] for magnesiowüstite, while constant values of $q$ and $k$ were used for silicate perovskite due to the absence of data.

By taking a RVH average, we assumed that various properties of a composite material are bounded by the corresponding properties of the constituents. While this is true for density and elastic moduli [Watt et al., 1976], this issue has not been thoroughly studied for the coefficient of thermal expansion, $\alpha$, and the thermoelastic parameters $\delta_{T}$ and $\gamma$. Anderson et al. [1996] argued that $\gamma$ of the magnesiowüstite-perovskite mix must be bounded by the corresponding values of the constituents. We expect this to be also true for the $\alpha$ and $\delta_{T}$. The calculated values of $\delta_{T}, \gamma$ and $\delta_{S}$ along the lower mantle adiabat are given in Figure 3.

For a successful dynamic model, values of the coefficient of thermal expansion are required throughout the mantle. We used a function in the form

$$
\alpha(z)=\frac{\alpha_{0}}{1+a z^{b}}
$$

to fit the calculated values of the coefficient of thermal expansion along the mantle adiabat (Figure 4). In equation (19) $\alpha_{0}$ is the value of expansivity at zero depth, $z$ is depth normalized by the radius of the Earth, and $a$ and $b$ are the fitting parameters to be determined. For the surface value of expansivity, $\alpha_{0}$ we take the zeropressure value of olivine at $T=1750 \mathrm{~K}$, which is about $4.5 \times 10^{-5} \mathrm{~K}^{-1}$ [Duffy and Anderson, 1989]. The best fit is found for $a=10.5, b=0.85$.

\section{GEODYNAMIC MODEL}

Thermo-chemical convection with two materials, each with distinct properties, is computed in a 2D cylindrical coordinate system $(r, \phi)$ for a variety of cases. An incompressible flow model (Boussinesq approximation) is used in the simulation. The system is governed by the following non-dimensional equations [Zhong and Gurnis, 1993], representing conservation of momentum

$$
\nabla \cdot(\mu \nabla u)=-\nabla p+\frac{1}{\zeta^{3}} \alpha(r) R a\left(T-\frac{1}{\alpha(r)} B C\right) \hat{\boldsymbol{r}}
$$

energy

$$
\frac{\partial T}{\partial t}=-(u \cdot \nabla) T+\nabla^{2} T+H
$$

and mass

$$
\nabla \cdot u=0
$$

In the above equations, $\hat{r}$ is a unit vector in the radial direction, $r$ is dimensionless radius, $\boldsymbol{u}$ is dimensionless velocity, $p$ is dimensionless pressure, $T$ is dimensionless temperature, $t$ is dimensionless time, and $\zeta$ is dimensionless depth of the core-mantle boundary. These Drrameters are related to the corresponding dimensic.lal 
Table 1. Thermoelastic parameters.

\begin{tabular}{lcccc}
\hline & $(\mathrm{Mg}, \mathrm{Fe}) \mathrm{O}(\mathrm{mw})$ & $(\mathrm{Mg}, \mathrm{Fe}) \mathrm{SiO}_{3}(\mathrm{pv})$ & $\mathrm{SiO}_{2}(\mathrm{st})$ & Reference \\
\hline & & & & \\
$V_{0}, \mathrm{~cm}^{3}$ & $11.25+1.0 \chi_{\mathrm{Me}}^{\mathrm{Mw}}$ & $24.447+1.143 \chi_{\mathrm{Fe}}^{\mathrm{Pv}}$ & 14.014 & 1,2 \\
$K_{S_{0}}, \mathrm{GPa}$ & $163-8 \chi_{\mathrm{Fw}}^{\mathrm{Mw}}$ & 264 & 305 & $3,4,2$ \\
$G_{0}, \mathrm{GPa}$ & $131-77 \chi_{\mathrm{Fe}}^{\mathrm{Mw}}$ & 177.3 & 217 & $3,4,2$ \\
$K_{S}^{\prime}$ & $3.8^{\mathrm{a}}$ & 4.0 & 5.3 & $5,6,2$ \\
$G^{\prime}$ & $1.7^{\mathrm{a}}$ & 1.6 & 1.8 & $5,6,2$ \\
$\Theta, \mathrm{K}$ & 945 & 1020 & 1192 & $7,8,3$ \\
$\gamma_{0}$ & 1.52 & 1.4 & - & 9,8 \\
$\delta_{T_{0}}$ & 5.0 & 4.5 & - & 7,8 \\
$\bar{\delta}_{T}$ & 4.9 & 5.0 & - & 7,8 \\
$\bar{\delta}_{S}$ & 3.15 & 2.7 & $2.7^{\mathrm{b}}$ & 7,10 \\
$\Gamma$ & 5.25 & $5.25^{\mathrm{c}}$ & $5.25^{\mathrm{c}}$ & 11 \\
$\bar{\Gamma}$ & 5.1 & $5.1^{\mathrm{c}}$ & $5.1^{\mathrm{c}}$ & 7 \\
$k$ & $k(T)^{\mathrm{d}}$ & 1.5 & - & 12,13 \\
$q$ & $q(\eta, T)^{\mathrm{e}}$ & 1 & - & 14,8 \\
& & & & \\
\hline
\end{tabular}

References: 1, Saxena [1996]; 2, Li et al. [1996]; 3, Duffy and Anderson [1989]; 4, Yeganeh-Haeri [1994]; 5, Isaak [1993]; 6, Zhao and Anderson [1994]; 7, Isaak et al. [1989]; 8, Anderson et al. [1996]; 9, Chopelas [1996]; 10, Bukowinski and Wolf [1990]; 11, Isaak et al. [1992]; 12, Anderson et al. [1992]; 13, Anderson and Masuda [1994]; 14, Anderson et al. [1993].

${ }^{a}$ Calculated mid-mantle value is used.

${ }^{b}$ Assumed to be the same as for $(\mathrm{Mg}, \mathrm{Fe}) \mathrm{SiO}_{3}$.

${ }^{\mathrm{c}}$ Assumed to be the same as for $\mathrm{MgO}$.

${ }^{\mathrm{d}} \mathrm{A}$ specific value is taken at any given temperature.

${ }^{\mathrm{e}} \mathrm{A}$ specific value is taken at any given compression and temperature.

values by means of the following scalings (asterisk denotes dimensional values):

$$
\begin{aligned}
r^{*} & =R_{0} r, \\
u^{*} & =\frac{\kappa}{R_{0}} u, \\
p^{*} & =\frac{\kappa \bar{\mu}}{R_{0}^{2}} p, \\
T^{*} & =T_{S}+\Delta T T, \\
t^{*} & =\frac{R_{0}^{2}}{\kappa} t,
\end{aligned}
$$

where $R_{0}$ is the radius of the Earth, $\kappa$ is the thermal diffusivity, $\bar{\mu}$ is the volume averaged mantle viscosity, $T_{S}$ is the temperature at the surface, and $\Delta T$ is the temperature increase across the mantle (Table 2).

Dynamic viscosity, $\mu$, and coefficient of thermal expansion, $\alpha$, in equation (20) are non-dimensionalized using the volume averaged values as characteristic scales:

$$
\begin{aligned}
\mu^{*} & =\bar{\mu} \mu, \\
\alpha^{*} & =\bar{\alpha} \alpha,
\end{aligned}
$$

where $\bar{\mu}$ and $\bar{\alpha}$ are volume averaged viscosity and expansivity of the mantle, respectively. We take $\bar{\mu}=$
$10^{21.5} \mathrm{~Pa} \cdot \mathrm{s}$, consistent with the inversion results of Mitrovica and Forte [1997]. The value of the volume averaged coefficient of thermal expansion, $\bar{\alpha}$, is calculated from the $1 \mathrm{D}$ adiabatic model presented above. In terms of the dimensionless radius, $r$, the depth dependence (19) of $\alpha$ can be written as:

$$
\alpha(r)=\frac{4.5 \times 10^{-5}}{1+10.5(1-r)^{0.85}} .
$$

Taking the volume average, we have:

$$
\bar{\alpha}=\frac{1}{V} \iint \log \alpha d V=1.535 \times 10^{-5} K^{-1} .
$$

For the purpose of convenience we will drop the ' $*$ ' for dimensional values in all consequent equations.

The effects of internal heating are not addressed in this study and only bottom-heated models are considered, so that $H=0$ in (21). Dimensionless parameter $R a$ in (20) is the thermal Rayleigh number which characterizes the vigor of convection in such a system. It is given by

$$
R a=\frac{g \bar{\alpha} \rho_{0} \Delta T D^{3}}{\kappa \bar{\mu}}
$$



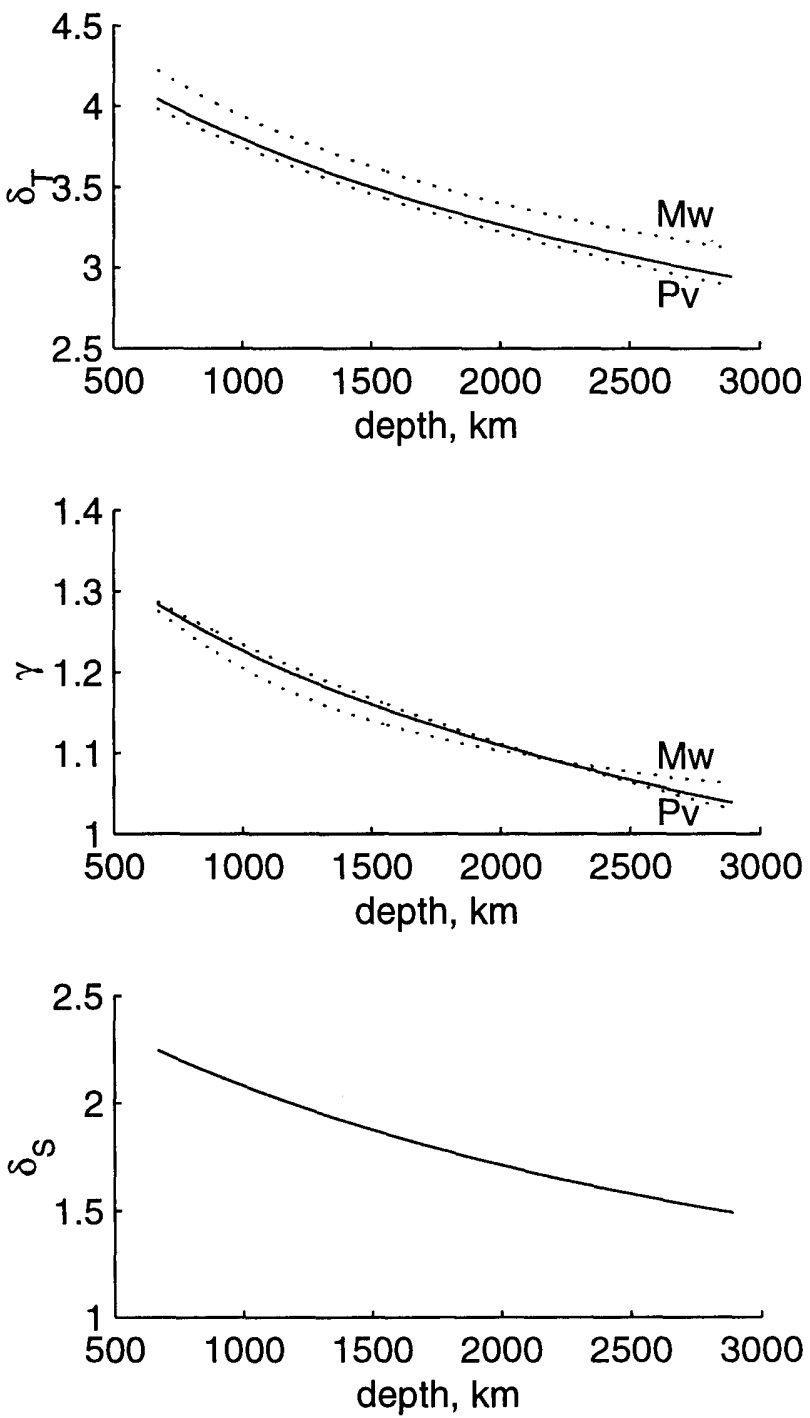

Figure 3. Thermoelastic parameters $\delta_{T}, \gamma$ and $\delta_{S}$, calculated along a mantle adiabat. Dotted lines give values for magnesiowüstite and silicate perovskite; solid lines represent the RVH average values. The values of $\delta_{S}$ were calculated using equation (15).

where $g$ is the gravitational acceleration, $\rho_{0}$ is the density of the ambient material, and $D$ is the depth of the core-mantle boundary. The anomalous material has density $\rho_{0}+\Delta \rho_{0}$ and its distribution is described by the composition function, $C(r, \phi)$, which takes values from 0 (ambient material) to 1 (anomalous material). The effect of the introduced anomalous material on the flow is characterized by the compositional Rayleigh number, $R a_{c}$, given by:

$$
R a_{c}=\frac{g \triangle \rho_{0} D^{3}}{\kappa \bar{\mu}}
$$

Parameter $B$ in (20) is the ratio of the two Rayleigh numbers, $B=R a_{c} / R a$. It characterizes the relative importance of the compositional and thermal buoyancy forces and is given by

$$
B=\frac{\triangle \rho_{0}}{\rho_{0} \bar{\alpha} \triangle T}
$$

The model domain is represented by a half-annulus (Figure 5) with the inner radius corresponding to the core-mantle boundary and the outer radius corresponding to the surface of the Earth. Plates are modeled by imposing velocity boundary conditions on the top, as shown in Figure 5a. Free slip conditions are used at the bottom and side walls of the domain. The value of imposed surface velocity was determined from a free-slip calculation with no temperature dependent viscosity to ensure that the plate neither speeds up nor slows down the flow from what would be expected in convection with a free slip top [Gurnis and Davies, 1986]. A velocity overshoot is added in the back-arc basin to initiate subduction and prevent the slab from being sucked up under the overriding plate [Christensen, 1996; Davies, 1997]. The trench migration velocity, $U_{\text {trench }}$, equal to

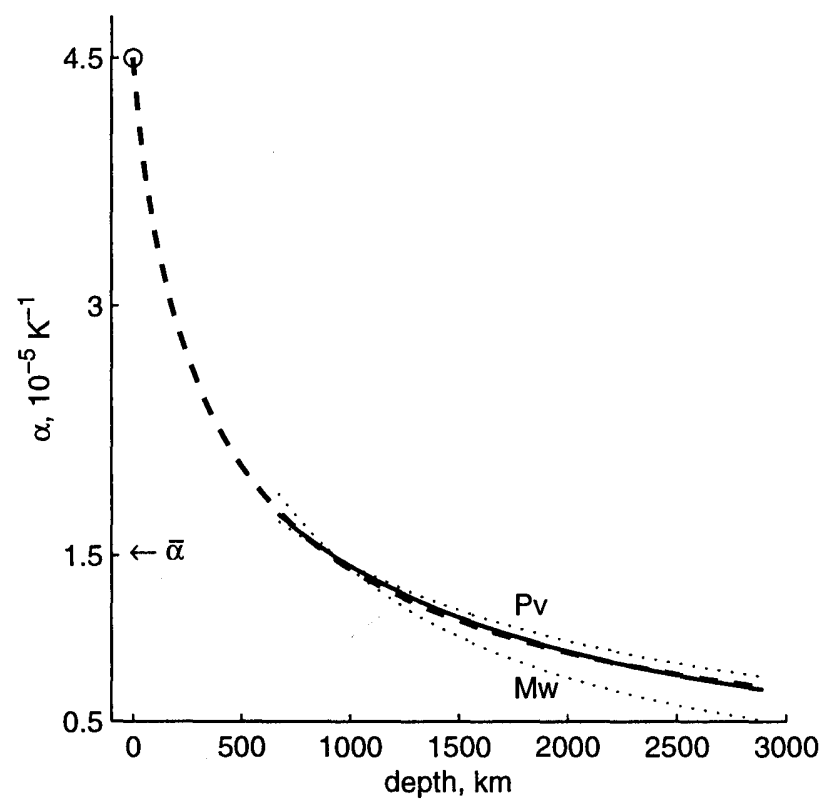

Figure 4. Coefficient of thermal expansion along a mantle adiabat. Dotted lines give values for magnesiowüstite and silicate perovskite; solid lines represent the RVH average values. The open circle represents the high-temperature value for olivine [Duffy and Anderson, 1989]. The dashed line gives the best fit using (19). The intercept on the vertical axis shows the volume averaged value used in dynamic models. 
Table 2. Values of parameters used in convection simulation

\begin{tabular}{lcc}
\hline Parameter & Symbol & Value \\
\hline Radius of the Earth & $R_{0}$ & $6371 \mathrm{~km}$ \\
Depth of the CMB & $D$ & $2891 \mathrm{~km}$ \\
Gravity acceleration & $g$ & $10 \mathrm{~m} / \mathrm{s}^{2}$ \\
Average mantle density & $\rho_{0}$ & $4.0 \mathrm{~g} / \mathrm{cm}^{3}$ \\
Average mantle viscosity & $\bar{\mu}$ & $10^{21.5} \mathrm{~Pa} \cdot \mathrm{s}$ \\
Thermal diffusivity & $\kappa$ & $10^{-6} \mathrm{~m}^{2} / \mathrm{s}$ \\
Average thermal expansivity & $\bar{\alpha}$ & $1.535 \times 10^{-5} \mathrm{~K}^{-1}$ \\
Temperature increase across the mantle & $\Delta T$ & $2900 \mathrm{~K}$ \\
Maximum velocity of subducting plate & $U_{\text {plate }}$ & $5 \mathrm{~cm} / \mathrm{yr}$ \\
Maximum trench migration velocity & $U_{\text {trench }}$ & $0.5 \mathrm{~cm} / \mathrm{yr}$ \\
\hline
\end{tabular}

the velocity of the overriding plate, is set to $10 \%$ of the surface velocity, $U_{\text {plate }}$, of the subducting plate.

The temperature is initially uniform throughout the interior of the mantle with superimposed top and bottom thermal boundary layers. The bottom boundary layer is 100 million years old. The thermal boundary layer for oceanic lithosphere is calculated using an infinite half-space cooling model with a velocity of $U_{\text {plate }}=5 \mathrm{~cm} / \mathrm{yr}$. The age of the lithosphere at the initial trench location is about 160 million years. To facilitate the detachment of the sinking slab from the overriding plate, the temperature on top of the overriding plate is set to the mantle interior temperature [Christensen, 1996; Davies, 1997]. The temperature variation across the bottom thermal boundary layer is taken equal to the variation across the lithosphere. The temperature in the mantle interior should correspond to the foot temperature of the mantle adiabat, $T_{f}=1750 \mathrm{~K}$, calculated above. This constraint and the choice of temperature variation across the bottom thermal boundary gives the value of the non-adiabatic temperature increase across the mantle, $\triangle T=2900 \mathrm{~K}$.

The imposed velocity of the subducting plate linearly increases from $0.05 U_{\text {plate }}$ to $U_{\text {plate }}$ over a time of 190 million years, roughly the time it takes the slab to reach the bottom of the mantle with such a velocity. Accordingly, the velocity of the overriding plate, which is equal to the velocity of the trench, increases from $0.05 U_{\text {trench }}$ to $U_{\text {trench }}$ over the same time interval. Such a gradual increase in imposed velocity helps to initiate subduction and is well justified physically, since the driving buoyancy force gradually increases with the increasing volume of subducted material. This is also consistent with a fully dynamic model of oceanic plates where plate margins are modeled with faults and surface velocities are model outcomes [Zhong and Gurnis, 1995].

A layer of distinct material with initial thickness $d_{0}^{\text {layer }}$ is introduced at the bottom of the mantle. The material interface is initially represented by a chain of
$N=2000$ particles, extending from the left side-wall to the right. Each particle is a passive tracer and is characterized by its coordinates $\left(r_{i}^{\text {int }}, \phi_{i}^{\text {int }}\right)$ in the system. Though this chain is not closed, the no-flux conditions at the bottom and the side-walls produce an effectively all-encompassing boundary. At any time a point lying above the chain is assumed to have an ambient composition, while a point lying below the chain is assumed to have a distinct composition.

The temperature and depth dependence of the dimensionless viscosity, $\mu$, is given by

$$
\mu=A \mu_{0}(r) \exp \left\{\frac{c_{1}}{c_{2}+\theta}-\frac{c_{1}}{c_{2}+0.5}\right\}
$$

The depth dependent part, $\mu_{0}(r)$, includes a factor of 10 increase across the $670 \mathrm{~km}$ depth:

$$
\mu_{0}(r)= \begin{cases}1 & \text { if } r>0.89 \\ 10 & \text { if } r<0.89\end{cases}
$$

Parameters $c_{1}$ and $c_{2}$ in (35) control the range of viscosity variation with temperature and the stiffness of the cold slab. We use $c_{1}=17.22$, which corresponds to an activation energy of $415 \mathrm{~kJ} \cdot \mathrm{mol}^{-1}$, and $c_{2}=0.64$. A cutoff value of $10^{3}$ is used. These parameters lead to 3 orders of magnitude in viscosity variation due to the temperature variations across the top boundary layer and another 2 orders of magnitude due to temperature variations in the bottom boundary layer.

The normalization parameter $A$ in (35) is chosen so that the following equality holds when averaged over the entire duration of the simulation:

$$
\frac{1}{V} \iint \log \mu d V=0
$$

where $V$ is the volume of the model domain. We find $A \approx 0.16$. Figure $5 \mathrm{~b}$ shows viscosity of the flow as the slab penetrates into the lower mantle. 
a)

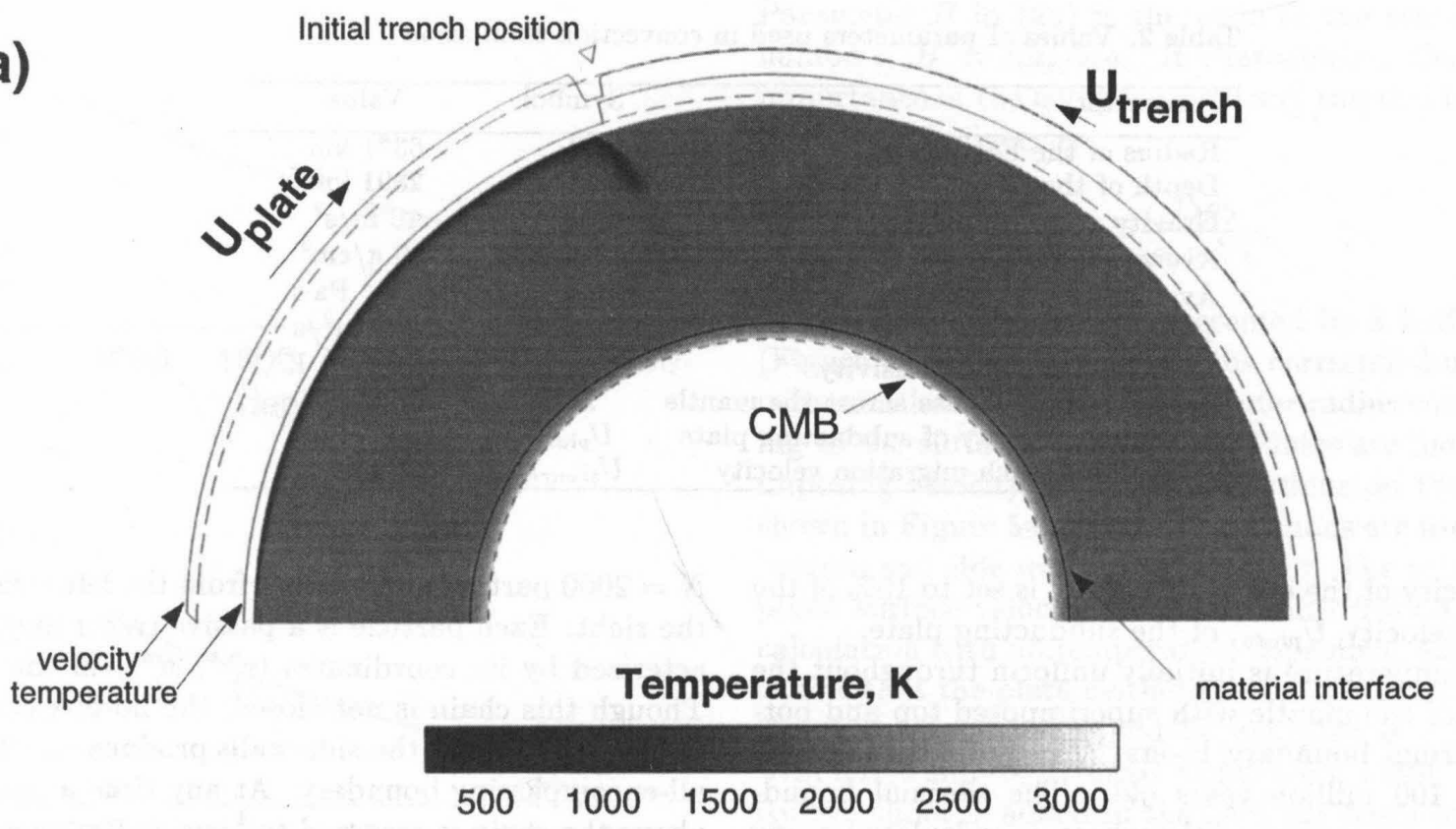

b)
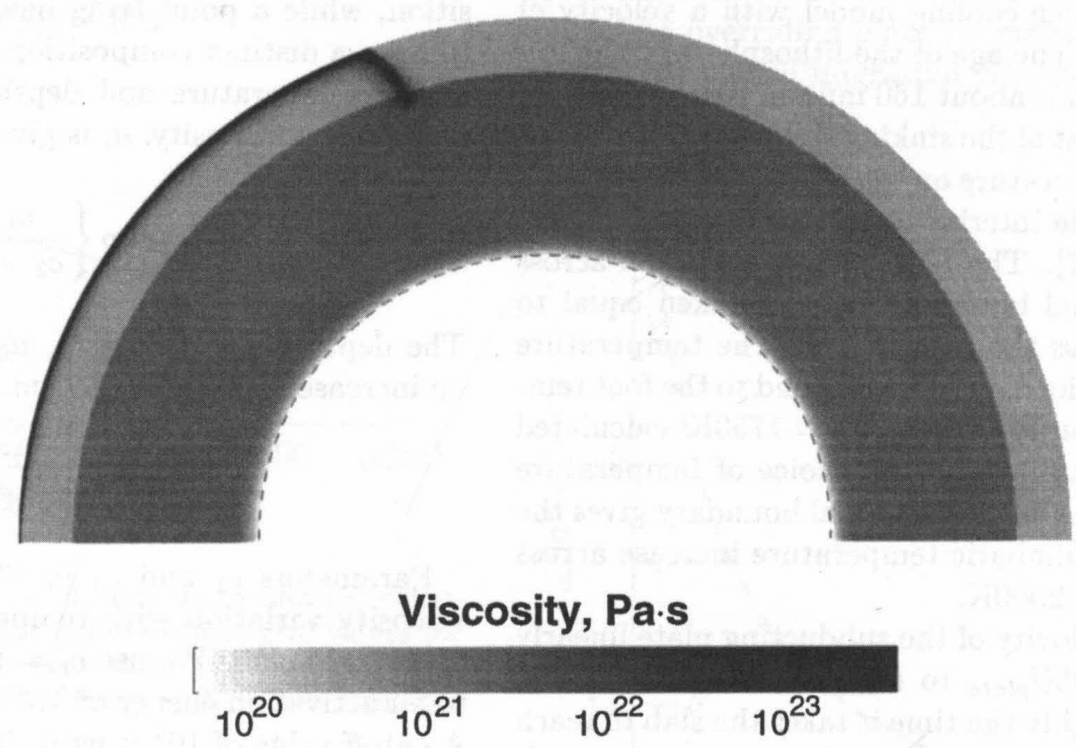

Figure 5. Dynamic model setup. a) Temperature field after 100 million years - just as the slab penetrates into the lower mantle. The value of the velocity overshoot in the back-arc region was scaled by a factor of 0.5 to give a clearer view of imposed plate velocities. b) Viscosity after 100 million years.

Equations (20)-(22) are solved using a finite-element code ConMan [King et al., 1990], as modified by Zhong and Gurnis [1993] for a cylindrical geometry. The finite elements mesh has 300 elements in the azimuthal direction and 100 elements in the vertical. The mesh is refined both vertically and horizontally to increase the resolution in the thermal boundary layers and in the area of subduction.
The particles in the chain, representing the material interface, are advected using a third-order accurate predictor-corrector method. Whenever the distance between two adjacent particles exceeds a specified limit, $\delta_{\max }$, a new particle is introduced into the chain and placed between the two particles, so that the resolution of the boundary never falls below $\delta_{\max }$. In our calculations we use $\delta_{\text {max }}=13 \mathrm{~km}$. An integration routine is 
used to calculate the ratio of each material in the finite element mesh. The associated compositional buoyancy is then fed back into the momentum equation (20). The accuracy of the material tracking algorithm was tested using steady-state divergence free analytic stream functions. The relative change in the volume, occupied by the distinct material did not exceed $1 \%$ after two overturn times, which is quite satisfactory for our purposes.

With all obvious limitations, introduction of compositional buoyancy into a convective system provides a nearly perfect resolution of the material interface, unlike solving an advective-diffusion equation or tracer particle methods. This jump in properties is essential for modeling seismic discontinuities. Moreover, the method does not seem to be vulnerable to the spurious settling problem encountered in various studies for the tracer particle techniques [Gurnis, 1986; Christensen and Hofmann, 1994; van Keken et al., 1997].

We compute twelve different models of thermo - chemical convection, varying in the form of depth dependence of the coefficient of thermal expansion, $\alpha(r)$, the properties of the material in the bottom layer and the layer thickness, $d_{0}^{\text {layer }}$ (Table 3 ). All studied cases have the same average thermal Rayleigh number. This is ensured by the normalization of the non-dimensional coefficient of thermal expansion, requiring its volume average to be 1 . In models with depth dependent thermal expansivity $\alpha$ varies with depth according to the adiabatic 1D model (30).

\section{COMPUTING 2D VELOCITY PERTURBATIONS}

To estimate the effect of the super-adiabatic temperatures and the inclusion of the chemically distinct material on the adiabatic 1D seismic velocities we use a Taylor series expansion of equations (16) and (17) restricted to linear terms:

$$
\begin{aligned}
\Delta V_{P}= & \frac{\partial V_{P}}{\partial K_{s}} d K_{s}+\frac{\partial V_{P}}{\partial G} d G+\frac{\partial V_{P}}{\partial \rho} d \rho \\
= & \frac{\partial V_{P}}{\partial K_{S}}\left(\frac{\partial K_{S}}{\partial T} d T+\frac{\partial K_{S}}{\partial C} d C\right) \\
& +\frac{\partial V_{P}}{\partial G}\left(\frac{\partial G}{\partial T} d T+\frac{\partial G}{\partial C} d C\right) \\
& +\frac{\partial V_{P}}{\partial \rho}\left(\frac{\partial \rho}{\partial T} d T+\frac{\partial \rho}{\partial C} d C\right) \\
= & \frac{1}{2} \frac{K_{S_{0}}}{\rho_{0} V_{P_{0}}}\left(\delta_{S} \alpha_{0} \Delta T_{n a}+\left(\epsilon_{K_{S}}-1\right) C\right) \\
& +\frac{2}{3} \frac{G_{0}}{\rho_{o} V_{P_{0}}}\left(\Gamma \alpha_{0} \Delta T_{n a}+\left(\epsilon_{G}-1\right) C\right)
\end{aligned}
$$

$$
\begin{aligned}
& -\frac{1}{2} V_{P_{0}}\left(\alpha_{0} \Delta T_{n a}+\left(\epsilon_{\rho}-1\right) C\right) \\
\Delta V_{S}= & \frac{\partial V_{S}}{\partial G} d G+\frac{\partial V_{S}}{\partial \rho} d \rho \\
= & \frac{1}{2} \frac{G_{0}}{\rho_{o} V_{S_{0}}}\left(\Gamma \alpha_{0} \Delta T_{n a}+\left(\epsilon_{G}-1\right) C\right) \\
& -\frac{1}{2} V_{S_{0}}\left(\alpha_{0} \Delta T_{n a}+\left(\epsilon_{\rho}-1\right) C\right)
\end{aligned}
$$

where $\epsilon_{\rho}=\rho_{d} / \rho_{a}, \epsilon_{K_{S}}=K_{S_{d}} / K_{S_{a}}, \epsilon_{G}=G_{d} / G_{a}$ are the elastic parameters ratios of the chemically distinct and the ambient materials, $\Delta T_{n a}$ is the non-adiabatic temperature, $C$ is the concentration of the distinct material and zero subscripts refer to the adiabatic $1 \mathrm{D}$ values. Values of $\delta_{S}$ at any given depth are taken consistent with the thermodynamic estimates along the adiabat (Figure 3). The value of $\Gamma$ is assumed to be constant with depth and equal to 5.25 .

The non-adiabatic temperature, $\Delta T_{n a}$, and the concentration of the distinct material, $C$, are obtained from the convection simulation. The non-adiabatic temperature is calculated as

$$
\Delta T_{n a}=T-T_{f}
$$

where $T_{f}$ is the foot temperature of the adiabat and $T$ is the temperature from convection computations.

\section{RESULTS}

The convection simulations have been integrated for 400 million years in each case. We now discuss the details of the results for a nominal case M9 with $\Delta \rho / \rho=$ $4 \%$ and $\alpha$ varying with depth according with (30). The slab starts its descent into the lower mantle at a very steep dip angle and stays almost vertical until its tip reaches the bottom. After that the lower part of the slab levels off and continues along the top of the bottom layer. The dip of the slab is reduced and some folding occurs. The slab has a substantial influence on the morphology of the bottom layer, depressing the material below and pushing it aside, towards the upwelling regions. This results in significant topography of the material interface, which is raised in the upwelling regions on both sides of the slab and depressed below the slab.

Results of the convection simulations for models M1, M2, M9 and M10 after 400 million years are given in Figure 6. In order to estimate the influence of model parameters $\left(\alpha, B\right.$, and $\left.d_{0}^{\text {layer }}\right)$ on the morphology of the bottom layer we computed the RMS topography of the 
Table 3. Values of parameters used in convection simulation

\begin{tabular}{lcccc}
\hline Convection Model & $\alpha$ & $d_{\mathbf{0}}^{\text {layer }}, \mathbf{k m}$ & $\Delta \rho_{0} / \rho_{0}$ & $\Delta d_{R M S}(400 \mathrm{Ma}), \mathrm{km}$ \\
\hline M1 & constant & 200 & $0 \%$ & 2750 \\
M2 & variable & 200 & $0 \%$ & 2017 \\
M3 & constant & 200 & $1 \%$ & 1622 \\
M4 & variable & 200 & $1 \%$ & 521 \\
M5 & constant & 200 & $2 \%$ & 346 \\
M6 & variable & 200 & $2 \%$ & 147 \\
M7 & variable & 200 & $3 \%$ & 118 \\
M8 & constant & 200 & $4 \%$ & 154 \\
M9 & variable & 200 & $4 \%$ & 103 \\
M10 & variable & 400 & $4 \%$ & 114 \\
M11 & variable & 200 & $5 \%$ & 91 \\
M12 & variable & 200 & $6 \%$ & 78 \\
\hline
\end{tabular}

For models with variable $\alpha$ the depth dependence of the coefficient of thermal expansion is consistent with the adiabatic 1D calculations (30). For constant $\alpha$ cases the volume averaged value of $\alpha$, given by (31) is used.

layer for all model cases, using

$$
\Delta d_{R M S}=\left[\frac{1}{N} \sum_{i=1}^{N}\left(r_{i}^{\text {int }}-d_{0}^{\text {layer }}-R_{0}+D\right)^{2}\right]^{\frac{1}{2}}
$$

The parameter $\triangle d_{R M S}$ characterizes the radial disturbance of the layer and is equal to zero for a uniform layer and increases with topography. The values of $\triangle d_{R M S}$ for all cases after 400 million years are given in Table 3 . Figure 7 gives the dependence of $\triangle d_{R M S}$ on the thermal expansion and the density contrast of the bottom material.

The topography of the layer is significantly reduced when the value of $\alpha$ at the bottom of the mantle is decreased. However, the effect of $\alpha$ on the slab dynamics is minor.

As Figure 7 shows, the stability of the layer dramatically increases when its density anomaly increases to about $2 \%$. In all cases with $\Delta \rho_{0} / \rho_{0}<2 \%$ most of the bottom layer was already destroyed after 400 million years of integration through entrainment of the material by plumes. Though smaller values of $\alpha$ increase the survival time of the layer, the decrease in $\alpha$ alone, without a density anomaly in the bottom material, is not able to keep the layer intact for long periods.

Figure 8 gives the values of $\Delta d_{R M S}$ as a function of time for six different cases. The topography of the material interface is controlled by two opposing processes. In subduction areas, the weight of the cold slab and the stress transmitted by the slab from the surface tend to depress the material boundary. Away from the slab, in the upwelling regions, the growing bottom thermal boundary layer increases the thermal buoyancy of the material, tending to elevate the boundary. The topography rapidly increases for about 100-200 million years as the slab descends to the bottom of the mantle and depresses the chemical layer. Then topography stays approximately constant for some time until the layer heats up and thermal buoyancy becomes substantial. A $1 \%$ chemical density contrast is obviously not enough to balance this buoyancy and the basal material is rapidly entrained by the upwellings after about 300 million years of model integration. For a $2 \%$ density contrast, at least after the period of integration used in our study, the layer survives at the bottom. However, all the material is swept towards the upwelling regions away from the core-mantle boundary below the slab.

An interesting change in dynamics occurs when the thickness of the layer is increased and a sufficient density contrast is applied. With an initial thickness of $400 \mathrm{~km}$ and a density contrast of $4 \%$ the slab fails to thin the layer significantly. The increased temperature drop across the bottom thermal boundary layer has a destabilizing influence [Lenardic and Kaula, 1994] and leads to the initiation of an upwelling below the slab (Figure 6d). This initiated upwelling increases the buoyancy of the layer below the slab, thus partially reducing the depression of the interface. However, this buoyancy increase is unable to reverse the effect of the slab and produce elevated topography below the slab.

The bottom panels in Figures 6 show seismic velocities through the radial profiles indicated in the top panels. The values of the adiabatic $1 \mathrm{D}$ velocities were corrected for the effects of temperature and chemistry using the procedure presented in Section 4. For cases M1 and $\operatorname{M} 2\left(\triangle \rho_{0} / \rho_{0}=0\right)$ the composition of the basal layer 

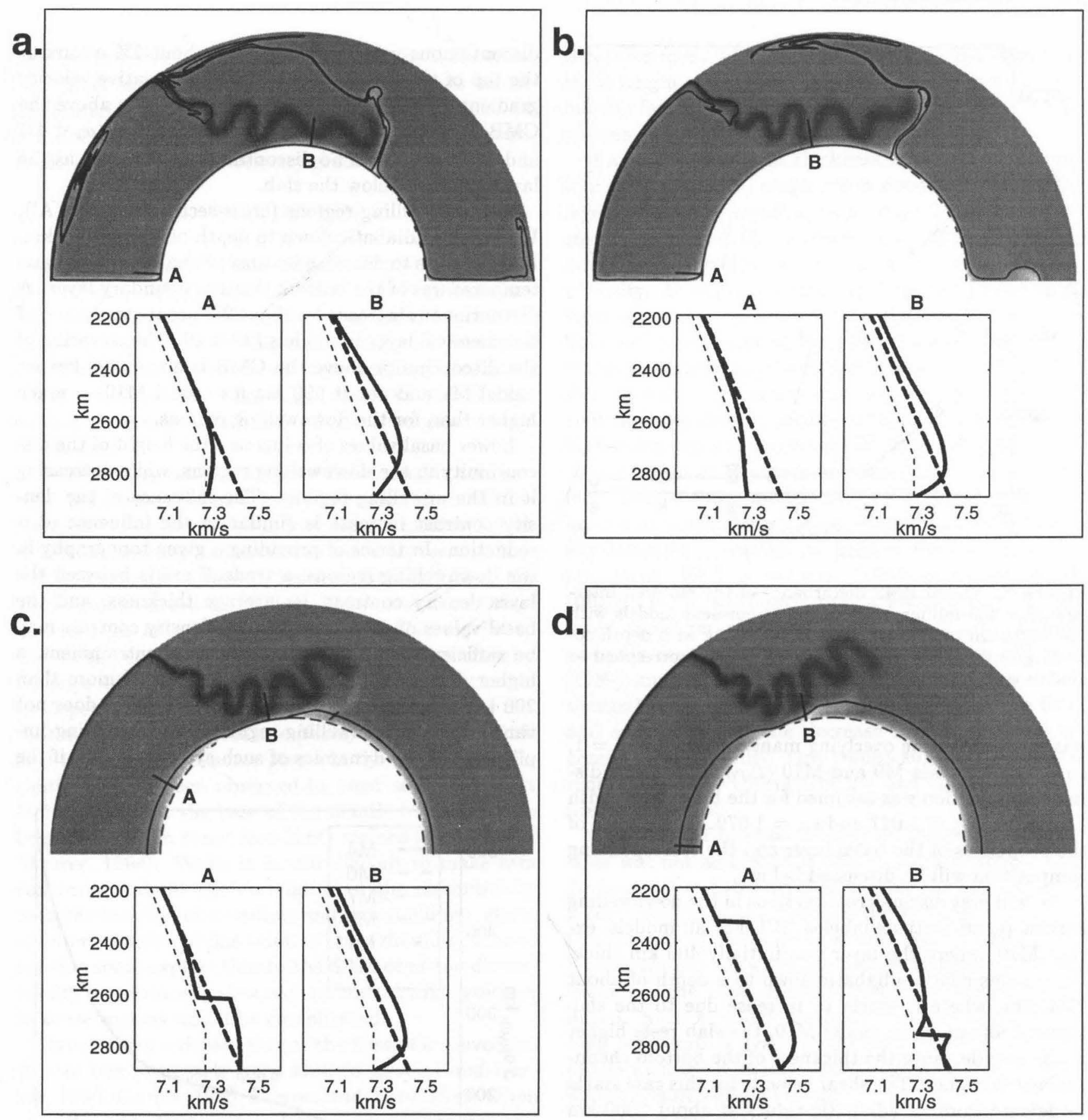

Temperature, $\mathrm{K}$

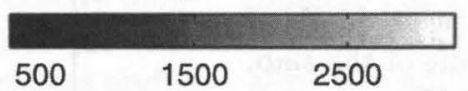

Figure 6. Four cases of convection simulation after 400 million years: a) model M1; b) model M2; c) model M9; d) model M10. Top panels show the temperature field and material interface (thin solid line). The core-mantle boundary is outlined by a dashed line. Bottom panels present seismic velocities (solid lines) computed for the cross-sections indicated in the top panels. For models M1 and M2 the basal material is assumed to be identical to the overlying mantle. For models M9 and M10 a stishovite and iron enrichment is assumed (composition indicated by a triangle in Figure 9). Cross-sections labeled 'A' correspond to upwelling regions, ' $\mathrm{B}$ ' - to downwelling regions. The adiabatic $1 \mathrm{D}$ model (thick dashed lines) and PREM values (thin dashed lines) values are given for reference. 


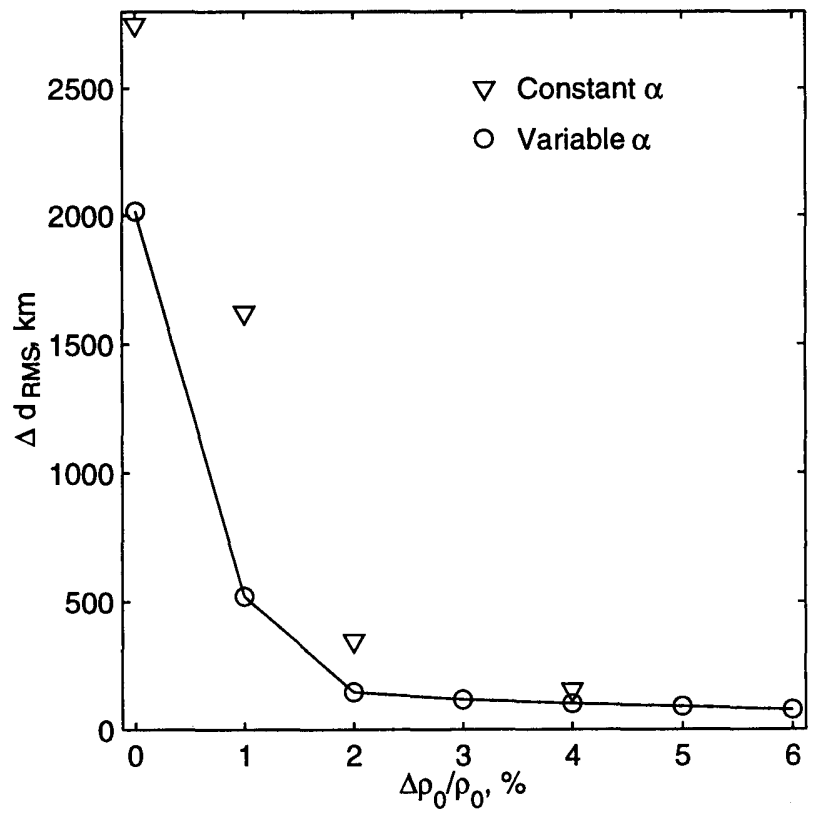

Figure 7. Radial RMS disturbance of the material interface after 400 million years. Circles represent models with the coefficient of thermal expansion varying with depth according to the adiabatic 1D model. Triangles correspond to models with constant $\alpha$.

was identical to the overlying mantle $\left(\epsilon_{\rho}=1, \epsilon_{K_{S}}=1\right.$, $\left.\epsilon_{G}=1\right)$. For cases M9 and M10 $\left(\Delta \rho_{0} / \rho_{0}=4 \%\right)$ a distinct composition was assumed for the basal layer, with $\epsilon_{\rho}=1.04, \epsilon_{K_{S}}=1.047$ and $\epsilon_{G}=1.079$. This choice of the properties of the basal layer and the corresponding composition will be discussed below.

We will first discuss cross-sections in the downwelling regions (cross-sections labeled 'B'). For all models, except M10, where the layer was initially $400 \mathrm{~km}$ thick, $V_{S}$ remains nearly adiabatic down to a depth of about $2200 \mathrm{~km}$, where it starts to increase due to the slab thermal anomaly. In model M10, the slab rests higher in the mantle, since the thickness of the bottom chemical layer is higher. The shear velocity for this case starts to deviate from its adiabatic values at about $2000 \mathrm{~km}$ depth. The fast velocity anomaly then continues to increase with depth, reaching its maximum at depth of 2200-2500 km, corresponding to the middle of the slab. At greater depths the trend reverses and $V_{S}$ returns to its adiabatic values. Both the increase and decrease take place over a depth range of about $200 \mathrm{~km}$, as the slab is diffuse. Following the attainment of adiabatic values, velocity starts to decrease with a large gradient due to the super-adiabatic temperatures of the bottom thermal boundary layer. In model M10 (Figure 6d) a discontinuous velocity increase by about $2 \%$ occurs at the top of the layer in the region of a negative velocity gradient. The elevation of this discontinuity above the CMB is about $150 \mathrm{~km}$. For models with $\triangle \rho_{0} / \rho_{0}<4 \%$ and $d_{0}^{\text {layer }}=200 \mathrm{~km}$ no discontinuity is observed as the layer vanishes below the slab.

In the upwelling regions (cross-sections labeled ' $\mathrm{A}$ '), $V_{S}$ remains adiabatic down to depth of about $2500 \mathrm{~km}$. It then starts to decrease because of the super-adiabatic temperatures of the bottom thermal boundary layer. A discontinuous increase by about $2 \%$ occurs at the top of the chemical layer in models M9-M10. The elevation of the discontinuity above the CMB is about $290 \mathrm{~km}$ for model M9 and about $590 \mathrm{~km}$ for model M10 - much higher than for the downwelling regions.

Lower basal values of $\alpha$ increase the height of the discontinuity in the downwelling regions, while decreasing it in the upwelling regions. The influence of the density contrast increase is similar to the influence of $\alpha$ reduction. In terms of providing a given topography in the downwelling regions, a tradeoff exists between the layer density contrast, its average thickness, and the basal values of $\alpha$. Although a 2\% density contrast may be sufficient to prevent the layer from entrainment, a higher density contrast and a thickness of more than $200 \mathrm{~km}$ are required to ensure that the layer does not vanish in the downwelling regions. An interesting implication of the dynamics of such systems is that if the

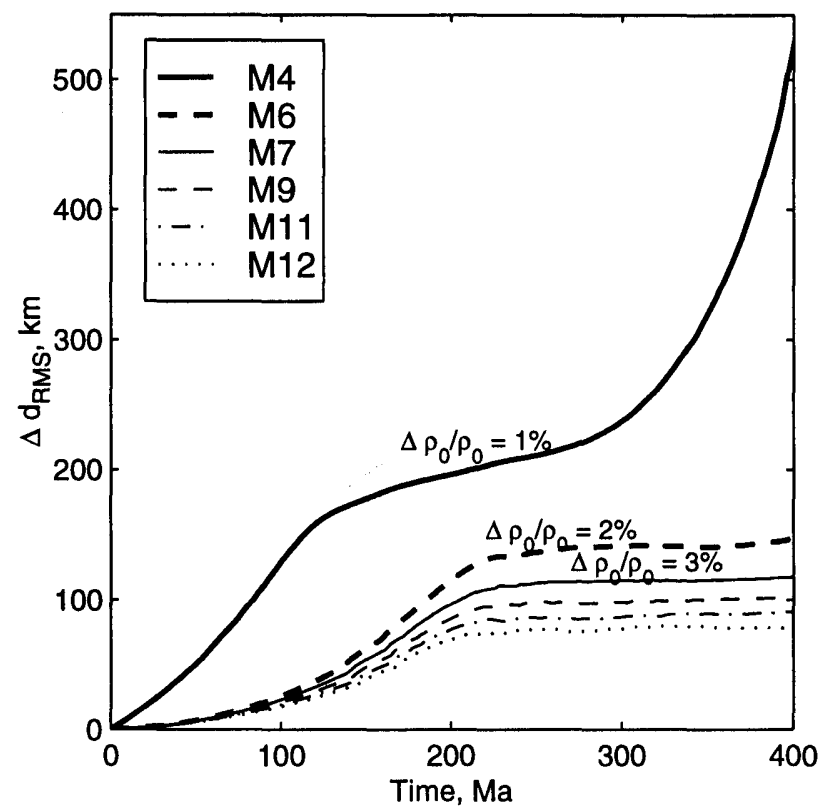

Figure 8. Disturbance of the basal layer as a function of time. 
layer survives for significant periods of time it becomes hot. This leads to high temperature gradients across the material interface in the downwelling regions, so that the discontinuous seismic velocity change occurs in the area of negative velocity gradient.

\section{DISCUSSION}

A chemical layer at the bottom of the mantle has been proposed in several studies [e.g., Davies and Gurnis, 1986; Christensen and Hofmann, 1994; Wysession, 1996] as causing the seismic discontinuity at the top of D". Using both previous and new results, is such an interpretation of the seismology consistent with the dynamics of the mantle and mineralogical and geochemical constraints?

Seismic body waves have been interpreted in terms of a $2-3 \%$ discontinuous velocity increase 150 to $350 \mathrm{~km}$ above the core-mantle boundary with a median height of $250 \mathrm{~km}$ in many regions of the world [Loper and Lay, 1995]. There are, however, reports of the height of the discontinuity as low as $130 \mathrm{~km}$ [Vidale and Benz, 1993] and as high as $450 \mathrm{~km}$ [Kendall and Shearer, 1994]. One of the controversial issues about the discontinuity is the problem of its intermittent nature (see discussion by Loper and Lay [1995]). It is still not clear if the discontinuity is a global feature [Nataf and Houard, 1993] or if it only exists in some places in the world. The discontinuity has been observed in most seismically fast (cold) regions at the base of the mantle but it has also been reported in some slow (hot) regions [Kendall and Shearer, 1994]. While it is still difficult to make firm conclusions about the correlation of the discontinuity with the location of upwelling and downwelling regions, an interpretation of this velocity jump should be able to provide some explanation to the absence of the discontinuity in seismically slow regions and why its detection in those regions would be complicated.

Dynamics of a dense layer at the base of a convection system has previously been studied [Davies and Gurnis, 1986; Gurnis, 1986; Hansen and Yuen, 1989; Olson and Kincaid, 1991]. All of the previous studies and our new work demonstrate the same qualitative influence of convection on the morphology of the layer. The layer is depressed below the cold downwellings and is swept towards hot regions where it may or may not be entrained by the upwellings. Independent of the layer formation, all dynamic models predict that the layer would be thinnest in the downwelling regions and thickest below the upwellings. This means that if the seismic discontinuity in D" occurs on top of a chemical layer, this layer must be at least $200-250 \mathrm{~km}$ thick since this is the height of the observed velocity jump in most seismically fast regions and regions which are most likely regions of downwellings.

If a layer of sufficient thickness is formed at the bottom of the mantle, under what conditions would the layer survive for a geologically long time without substantial recharge? This problem was studied by Davies and Gurnis [1986] in convection models with constant viscosity. It was found that an initially $300 \mathrm{~km}$ thick layer which is $2-3 \%$ heavier than the surrounding mantle would survive for at least 250 million years. Laboratory experiments [Olson and Kincaid, 1991] suggest that at least $2 \%$ density anomaly is required to prevent the layer from immediate overturn. A layer with a higher density contrast would be stable against mixing on a geophysically significant time scale. Sleep [1988] formulated a single model of the entrainment of a dense layer and concluded that an approximately $6 \%$ density anomaly is required to prevent the layer from entrainment. Kellogg and King [1993] gave a similar estimate (3-6\%) and noted that a low viscosity bottom layer would retard entrainment, reducing the density anomaly, required for layer stability. Hansen and Yuen [1989] emphasized the importance of depth dependent thermal expansion on the dynamics of the dense layer and suggested that the decrease in $\alpha$ with depth increases layer stability. Our results suggest a minimum required density contrast of $2 \%$ and agree with most previous studies.

The effect of internal heating on the stability of the layer was not addressed in this study. Christensen and Hofmann [1994] showed that varying the amount of internal heating in their models did not significantly affect the rate of entrainment of the layer. Tackley [1998] demonstrated that when the basal heating is completely excluded, the rate of entrainment is considerably reduced. Such a model is unlikely true for the Earth as high temperature gradients probably exist at the base of the mantle [Williams, 1998]. However this issue requires a more detailed study.

Another important limitation of this study is a twodimensional approximation. Results of Tackley [1998] show that the rate of entrainment is similar in equivalent $2 \mathrm{D}$ and $3 \mathrm{D}$ models. So while the dynamics in three dimensions can be qualitatively different from two-dimensional convection, our conclusions about the layer stability requirements will probably hold for three dimensions.

If the material is efficiently entrained by the upwellings, considerable recharge of the layer is required 
so that the layer can exist for long periods of geological time. The sources of such recharge may include products of reactions between the core and mantle [Knittle and Jeanloz, 1991; Kellogg and King, 1993] or rock subducted from the surface [Gurnis, 1986; Christensen and Hofmann, 1994].

Modeling results of Kellogg and King [1993] indicate that if the layer is recharged from the core a density contrast of $3-6 \%$ is required for the material in the layer. Otherwise, entrainment processes dominate and the layer is destroyed. Such a mechanism would create a layer less than $100 \mathrm{~km}$ thick throughout Earth history - about half of what would be required to explain the D" discontinuity. If the material of the layer is intermixed by convection with the material above, creating a thicker layer with an intermediate density [Kellogg and King, 1993], the resulting layer would probably have a diffuse boundary and would be unable to produce seismic reflections.

Recharge by subduction was studied by Gurnis [1986] and Christensen and Hofmann [1994]. The problem with this scenario is that at the CMB only the original crustal layer of the subducting slab is expected to be denser than the surrounding material. This posteclogite phase of basalt comprising the oceanic crust was estimated by Christensen and Hofmann [1994] to be about $2 \%$ denser than the surrounding material under the conditions relevant at the CMB. Convection models with constant viscosity demonstrated that separation of this dense phase from the rest of the slab is required in order to produce some chemical pool at the bottom of the mantle [Gurnis, 1986]. Incorporating the layered structure into numerical models, Richards and Davies [1989] suggested that no separation between the original crust and depleted lithosphere would occur in the upper mantle and the transition zone. This result was corroborated by Gaherty and Hager [1994], who showed that slab dynamics in the upper part of the mantle is controlled by the thermal buoyancy and not the density differences associated with chemical lamination of the slab. However, Christensen and Hofmann [1994] suggested that the separation of the dense phase from the slab may occur at the bottom of the mantle and hypothesized that such separation would indeed produce a layer of post-eclogitic rock on top of the core-mantle boundary. It was found, however, that only a small fraction of the subducted crust would accumulate at the bottom of the mantle, while the rest would be remixed into the mantle. This fraction strongly depends on the Rayleigh number and is less than $2 \%$ for $R a \sim 10^{7}$ [Christensen and Hofmann, 1994]. Using the present day rate of crust subduction of $20 \mathrm{~km}^{3} / \mathrm{yr}$ we can esti- mate that such a process would require $80-100$ billion years to form a layer $200-250 \mathrm{~km}$ thick. Although the mantle dynamics was likely to be different in the early Earth history, we doubt that such mechanism could produce sufficient amount of material to form the D" layer. Moreover, because of intensive mixing of the subducted crust a rather diffuse boundary is expected.

If a chemical layer with a thickness which matches the height of the D" discontinuity exists, what could the layer be comprised of? The material has to satisfy the following two properties: 1 ) in order to survive for a geologically significant period of time, it must be at least $2 \%$ denser than the surrounding material and 2) in order to match seismological constraints, it must have seismic velocities $2-3 \%$ higher than a lower mantle of "ambient" composition. Iron enrichment is the most effective mechanism for a density increase. However, Fe enrichment of the magnesiowüstite and silicate perovskite lower mantle results in lower velocities of the resulting assemblage. A possible exception is the lowspin $\mathrm{Fe}^{2+}$ [Gaffney and Anderson, 1973]. A spin-pairing transition in $\mathrm{FeO}$ was suggested by several studies [e.g., Strens, 1969; Gaffney and Anderson, 1973; Sherman, 1988]. However, not only are the elastic properties of the low-spin phase unknown, the transition pressure itself is a subject of an ongoing discussion [e.g., Sherman and Jansen, 1995]. In a recent study Cohen et al. [1997] predicted from first-principles calculations that a magnetic collapse can occur in iron under the lower mantle conditions. However, no experimental evidence for such transitions has yet been found.

The subducted post-eclogite ocean crust, as estimated by Christensen and Hofmann [1994], is about $2 \%$ denser than the magnesiowüstite and silicate perovskite lower mantle and, as estimated by Wysession [1996], has a $2-3 \%$ faster seismic velocity. However, as was discussed above, a sufficiently thick layer of subducted ocean crust at the base of the mantle is unlikely.

Vidale and Benz [1993] estimated that a $25 \%$ enrichment in stishovite of the basal layer could explain the seismic data. Using a third-order Birch-Murnaghan equation of state we calculated the properties of $\mathrm{SiO}_{2}$ stishovite at pressures $250 \mathrm{~km}$ above the core mantle boundary. The estimated density of stishovite at that depth is about $3 \%$ lower than the density of a magnesiowüstite and silicate perovskite assemblage with $\chi_{\mathbf{P v}}=0.55$ and $\chi_{\mathrm{Fe}}=0.11$, which is the composition that provides a good fit to PREM, as estimated in our study. Several post-rutile structures have been proposed for $\mathrm{SiO}_{2}$ and two were experimentally identified. These are a $\mathrm{CaCl}_{2}$-type structure [Tsuchida and Yagi, 1989] and a $\alpha-\mathrm{PbO}_{2}$-type structure [Dubrovinsky 
et al, 1997; Karki et al., 1997a; Karki et al., 1997b]. However, the volume change associated with each of the associated transitions is less than $1 \%$ [Tsuchida and Yagi, 1989; Karki et al., 1997a]. This means that even if all silica at the base of the mantle is transformed into $\mathrm{CaCl}_{2}$ structure, as suggested by Kingma et al. [1995], or even into $\alpha-\mathrm{PbO}_{2}$ structure, it will remain less dense than the magnesiowüstite and silicate perovskite assemblage. It is obvious that silica enrichment alone cannot provide a dynamically stable layer and some iron enrichment is also required.

Any extra iron in D" is likely to enter $\mathrm{FeO}$, though some amount of FeSi alloy may also be present [Knittle and Jeanloz, 1991]. So iron enrichment is equivalent to the increase in $\mathrm{FeO}$ content. This means that if any high pressure phases of $\mathrm{FeO}$ exist, their properties may significantly affect the amount of $\mathrm{FeO}$ required to dynamically stabilize the layer. Two phase transitions in $\mathrm{FeO}$ at high pressures have been reported. One, taking place around $16 \mathrm{GPa}$, has been associated with a distortion of the rock-salt-type cell into a rhombohedral cell [Zou et al., 1980; Yagi et al., 1985]. Another transition observed at pressures about $70 \mathrm{GPa}$ [Jeanloz and Ahrens, 1980; Knittle and Jeanloz, 1986; Yagi et al., 1988] is interpreted as a transition to a NiAs phase [Fei and Mao, 1994]. The phase transition at $70 \mathrm{GPa}$ is accompanied by a density increase of at least 10-16\% [Jackson and Ringwood, 1981]. However, the elastic moduli are similar for the low pressure and high pressure polymorphs, so that velocity is expected to decrease in the transition [Jeanloz and Ahrens, 1980]. A solid solution of $\mathrm{MgO}$ and $\mathrm{FeO}$ may have a significantly different phase diagram. Shock compression of $\mathrm{Mg}_{0.6} \mathrm{Fe}_{0.4} \mathrm{O}$ to $200 \mathrm{GPa}$ [Vassiliou and Ahrens, 1982] did not find a convincing evidence for any phase change similar to the phase transition of $\mathrm{FeO}$ at $70 \mathrm{GPa}$. This questions the existence of high pressure modifications of magnesiowüstite in the lower mantle and suggests that the density and elastic moduli of any such phases must be similar to the low-pressure phase.

We calculate the influence of stishovite and iron enrichment on the density and shear velocity of the adiabatic 1D model (Figure 9). The filled circle represents the composition of the computed adiabatic 1D model (a silicate perovskite and magnesiowüstite assemblage with $\chi_{\mathrm{Pv}}=0.55$ and $\chi_{\mathrm{Fe}}=0.11$ ). The solid contours indicate the influence of the change in iron content or stishovite enrichment on the density of the assemblage, while the dashed contours indicate the effect on the shear velocity. The light shaded area shows the range of compositions consistent with the requirements for a dynamic stability of the chemical layer $\left(\triangle \rho_{0} / \rho_{0} \geq 2 \%\right)$. The medium shaded region represents the range of compositions consistent with a seismologically observed shear velocity increase by $1-3 \%$. The intersection of the two regions, the dark shaded region, represents the range of compositions that are both dynamically and seismologically consistent. According to this analysis, $25-60 \%$ by volume of stishovite, accompanied by a significant increase of $\chi_{\mathrm{Fe}}$ could produce a layer that would provide the required velocity jump and be dynamically stable. Due to the very small volume change and predicted average shear modulus softening of $10-30 \%$ estimated by Jeanloz [1989] for rutile $\rightarrow \mathrm{CaCl}_{2}$ transition, transformation of silica into one of the mentioned above post-rutile phases probably would not affect the estimates significantly or considerably reduce the required amount of silica.

The source of the extra $\mathrm{SiO}_{2}$ and $\mathrm{FeO}$ is not clear. Several possibilities may exist. It was first suggested by Birch [1952] that silicates would break down into simple oxides under high pressures. A later study by

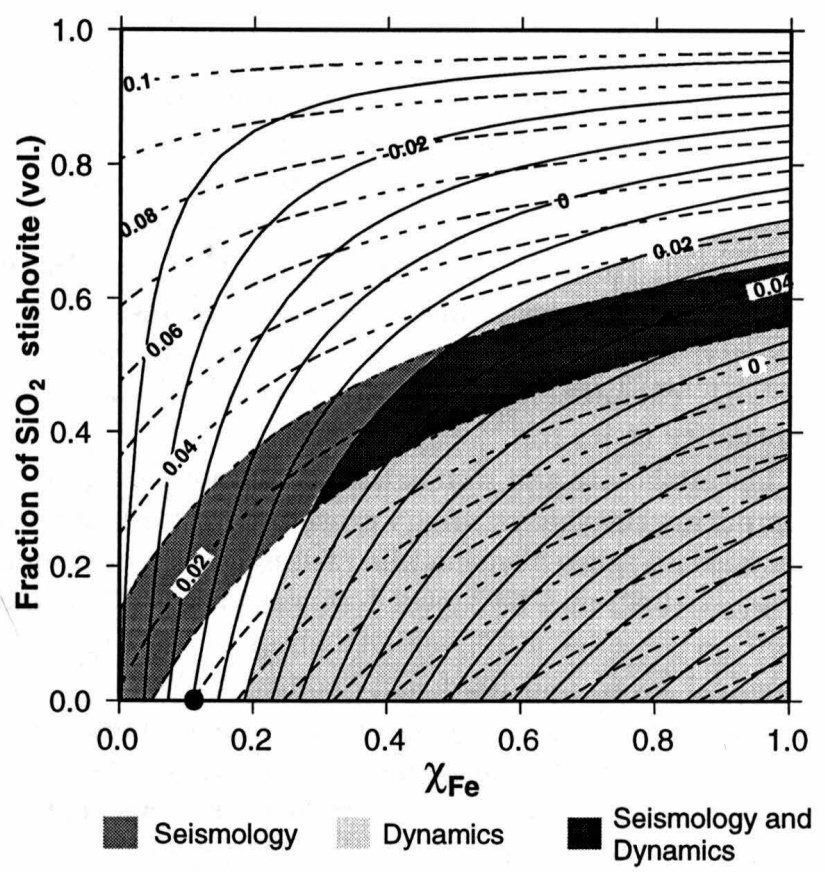

Figure 9. Calculated relative change in density (solid contours) and shear velocity (dashed contours) of the adiabatic 1D model, resulting from a stishovite enrichment and change in Fe content. The light shaded area indicate the range of dynamically consistent compositions; the medium shade indicates seismologically consistent composition; the range of compositions that are consistent with both seismology and dynamics is marked by the dark shade. The filled circle indicates the composition of the adiabatic $1 \mathrm{D}$ model. The filled triangle marks the composition used to calculate seismic velocities for dynamic models with $\Delta \rho_{0} / \rho_{0}=0.04$. 
Stixrude and Bukowinski [1990] supported the dissociation of silicate perovskite to $\mathrm{SiO}_{2}$ and $(\mathrm{Mg}, \mathrm{Fe}) \mathrm{O}$ under the D" conditions. Such dissociation would produce a seismic velocity increase by about $3 \%$, as estimated by Wysession [1996]. Stixrude and Cohen [1993] argue against such decomposition under lower mantle conditions, but more the recent experimental work of Meade et al. [1995] shows evidence for a dissociation of silicate perovskite into an assemblage of perovskite and mixed oxides. However, estimates show that even if $\mathrm{SiO}_{2}$ is transformed into one of the known post-rutile structures, perovskite remains denser than the isochemical mixture of oxides [Tsuchida and Yagi, 1989]. This means that silicate perovskite is expected to be stable under the lower mantle conditions, unless some denser phases of silica and magnesiowüstite exist.

Chemical reactions between the core and the mantle material may be another source of $\mathrm{SiO}_{2}$ and $\mathrm{FeO}$ in $\mathrm{D}^{\text {" }}$ [Knittle and Jeanloz, 1991], but, as was discussed above, this mechanism is unlikely to be sufficiently efficient to create enough reaction products to generate a layer of required thickness.

The layer may also have been created in the process of the Earth differentiation. A model of inhomogeneous accretion predicts a layer of refractory material at the top of the CMB, since this material is expected to be about $2 \%$ denser than normal mantle [Ruff and Anderson, 1980]. However, as estimated by Ruff and Anderson, the refractories would have about $5 \%$ lower seismic velocity, so such composition is an unlikely candidate for a D" chemical layer consistent with the seismic discontinuity at its top.

The stishovite and iron enriched composition used for computing the shear velocity cross-sections (Figure 6) is marked in Figure 9 with a filled triangle. It corresponds to $\chi_{\mathrm{Fe}}=0.82$ and $58 \%$ (vol.) of stishovite. This composition provides a $2 \%$ velocity jump at the top of the chemical layer, and its density contrast $(4 \%)$ is consistent with the value of $\Delta \rho_{0} / \rho_{0}$ used in the dynamic modeling. However, the only case that predicts the height of the discontinuity consistent with seismological observations in the seismically fast (cold) regions is model M10, where the layer was originally $400 \mathrm{~km}$ thick. All other cases predict a discontinuity too close (less than $100 \mathrm{~km}$ ) to the CMB or the discontinuity is missing. This implies that, unless even higher density contrast is assumed for the basal material, the chemical layer must be about $400 \mathrm{~km}$ thick on average to be consistent with seismological observations.

What possible reasons may complicate seismological detection of the top of such a dense chemical layer in seismically slow regions? Source-receiver pair geography may play some role [Kendall and Shearer, 1994]. It is also very possible that the seismically slow regions in D" where no evidence for the discontinuity exists are chemically different from the rest of the basal material. One possibility is iron-rich phases coming from the core. This material, when mixed with the dense and seismically fast basal layer, would reduce its velocity and this reduction may be sufficient to neutralize the jump at the top of the basal layer. Hot upwellings may facilitate this process. Another possible mechanism that may potentially complicate detection is defocusing of seismic waves by a convex top boundary of the layer, expected in the upwelling regions. However, our models show a very smooth material interface with very low curvature. Such an effect is unlikely to play any significant role.

A viable alternative to a chemical layer is a phase transition. This interpretation of the seismic discontinuity is favored by Nataf and Houard [1993] and was considered by Wysession [1996]. No relevant phase change has been experimentally confirmed. But the hypothetical possibilities include the breakdown of silicate perovskite into the constituent oxides [Wysession, 1996] or some, not yet known, transition in perovskite or magnesiowüstite.

\section{CONCLUSIONS}

Our current state of knowledge on D" does not allow us to accept or rule out a chemical origin of the seismic discontinuity at the top of the $D$ " region. Tighter constraints are required on the high pressure properties of minerals relevant to the lower mantle, the phase diagrams and the change of volume and elastic moduli associated with various transitions. We still poorly understand the extent of material exchange between the core and the mantle and the scope and rate of chemical reactions at the $\mathrm{CMB}$, as well as the evolution of the Earth as a whole. However, dynamic modeling, seismic observations and general considerations argue against a simple chemical layer. Some of the arguments are the following:

1. Dynamic models suggest that at least a $2 \%$ density contrast is required in order for a chemical layer to survive for geologically significant periods of time. This, combined with a seismic observations of a $2-3 \%$ velocity increase, requires a very large impedance change. A complex change in composition is probably required, since enrichment or depletion in a single mineral is unlikely to 
be able to produce the required impedance contrast.

2. An even higher density contrast ( $4 \%$ or more) and initial thickness of about $400 \mathrm{~km}$ are required to ensure the layer exists under the downwellings. A mechanism able to form a layer of such thickness throughout the history of the Earth is not known. Estimates show that neither subducted material, nor the products of reactions with the core can supply enough material. Refractories emplaced from the core, although they may have the required density contrast, are expected to have lower velocities than normal mantle and thus are unlikely candidates.

3. Dynamics of a dense layer implies that the material interface in the downwelling regions is accompanied by a high vertical temperature gradient. This means that the discontinuous velocity increase will occur in a region with negative vertical gradient of seismic velocity. Such a model would require a higher velocity jump $(>3 \%)$ than the Lay and Helmberger [1983] model in order to produce sufficiently strong reflections, consistent with seismic observations. This requires an even higher impedance contrast.

4. It is difficult to explain why a seismic discontinuity has not been confirmed on top of D" in any seismically slow (hot) region of the world. A chemical layer of significant thickness in the downwelling regions, completely thinned out in the upwelling regions, is not dynamically plausible. Dynamic models predict a very smooth material interface in the upwelling regions, so any defocusing effects cannot be important.

5. A simple chemical layer cannot explain other seismological observations relevant to D", such as the high heterogeneity or anisotropy.

If $\mathrm{D}$ " is a chemical layer, it is most likely chemically heterogeneous and its dynamics is much more complex than shown by our models or any other models to date. Its morphology is probably influenced by other processes so far ignored and, perhaps, still unknown processes that are yet to be discovered.

Acknowledgments. We are very grateful to Don Anderson and Don Helmberger for stimulating discussions. We also thank Don Anderson and an anonymous reviewer for reading the manuscript and providing a number of valuable comments. This research was funded by NSF grant EAR9629279. This represents contribution number 6217 of the Division of Geological and Planetary Sciences, California Institute of Technology.

\section{REFERENCES}

Agnon, A., and M. S. T. Bukowinski, $\delta_{S}$ at high pressure and $d \ln V_{S} / d \ln V_{P}$ in the lower mantle, Geophys. Res. Lett., 17, 1,149-1,152, 1990.

Anderson, D. L., A seismic equation of state II. Shear properties and thermodynamics of the lower mantle, Phys. Earth Planet. Inter., 45, 307-323, 1987.

Anderson, D. L., Temperature and pressure derivatives of elastic constants with application to the mantle, J. Geophys. Res., 93, 4,688-4,700, 1988.

Anderson, O. L., Equation for thermal expansivity in planetary interiors, $J$. Geophys. Res., 72, 3,661-3,668, 1967.

Anderson, O. L., and D. G. Isaak, The dependence of the Anderson-Grüneisen parameter $\delta_{T}$ upon compression at extreme conditions, J. Phys. Chem. Solids, 54, 221-227, 1993.

Anderson, O. L. and K. Masuda, A thermodynamic method for computing thermal expansivity, $\alpha$, versus $T$ along isobars for silicate perovskite, Phys. Earth Planet. Inter., 85, 227-236, 1994.

Anderson, O. L., K. Masuda, and D. Guo, Pure silicate perovskite and the PREM lower mantle model: a thermodynamic analysis, Phys. Earth Planet. Inter., 89, 35-49, 1995.

Anderson, O. L., K. Masuda, and D. G. Isaak, Limits on the value of $\delta_{T}$ and $\gamma$ for $\mathrm{MgSiO}_{3}$ perovskite, Phys. Earth Planet. Inter., 98, 31-46, 1996.

Anderson, O. L., H. Oda, and D. Isaak, A model for the computation of thermal expansivity at high compression and high temperatures: $\mathrm{MgO}$ as an example, Geophys. Res. Lett., 19, 1,987-1,990, 1992.

Anderson, O. L., H. Oda, A. Chopelas, and D. G. Isaak, A thermodynamic theory of the Grüneisen ratio at extreme conditions: $\mathrm{MgO}$ as an example, Phys. Chem. Miner., 19, 369-380, 1993.

Birch, F., Elasticity and constitution of the Earth's interior, J. Geophys. Res., 57, 227-286, 1952.

Bukowinski, M. S., and G. H. Wolf, Thermodynamically consistent decompression: Implications for lower mantle composition, J. Geophys. Res., 95, 12,583-12,593, 1990.

Burdick, L., and D. L. Anderson, Interpretation of velocity profiles of the mantle, J. Geophys. Res., 80, 1,070-1,074, 1975.

Butler, R., and D. L. Anderson, Equation of state fits to the lower mantle and outer core, Phys. Earth Planet. Inter., $17,147-162,1978$.

Chopelas, A., Thermal expansivity of lower mantle phases $\mathrm{MgO}$ and $\mathrm{MgSiO}_{3}$ perovskite at high pressure derived from vibrational spectroscopy, Phys. Earth Planet. Inter., 98, 3-15, 1996.

Chopelas, A., and R. Boehler, Thermal expansivity in the lower mantle, Geophys. Res. Lett., 19, 1,983-1,986, 1992.

Christensen, U. R., The influence of trench migration on slab penetration into the lower mantle, Earth Planet. Sci. Lett., 140, 27-39, 1996.

Christensen, U. R., and A. W. Hofmann, Segregation of subducted oceanic crust in the convecting mantle, J. Geophys. Res., 99, 19,867-19,884, 1994.

Cohen, R. E., I. I. Mazin, and D. G. Isaak, Magnetic collapse in transition metal oxides at high pressure: Implications for the Earth, Science, 275, 654-657, 1997. 
Davies, G. F., Incorporating plate into mantle convection models (abstract). In: AGU Chapman Conference. The History and Dynamics of Global Plate Motions, p. 42, 1997.

Davies, G. F., and A. M. Dziewonski, Homogeneity and constitution of the Earth's lower mantle and outer core, Phys. Earth Planet. Inter., 10, 336-343, 1975.

Davies, G. F., and M. Gurnis, Interaction of mantle dregs with convection: Lateral heterogeneity at the core-mantle boundary, Geophys. Res. Lett., 13, 1,517-1,520, 1986.

Ding, X., High resolution studies of deep Earth structure, Ph.D. thesis, 108 pp., Calif. Inst. of Technology, June 1997.

Dubrovinsky, L. S., S. K. Saxena, P. Lazor, R. Ahuja, O. Eriksson, J. M. Wills, and B. Johansson, Experimental and theoretical identification of a new high-pressure phase of silica, Nature, 388, 362-365, 1997.

Duffy, T. S. and T. J. Ahrens, Thermal expansion of mantle and core materials at very high pressures, Geophys. Res. Lett., 20, 1,103-1,106, 1993.

Duffy, T. S., and D. L. Anderson, Seismic velocities in mantle minerals and the mineralogy of the upper mantle, $J$. Geophys. Res., 94, 1,895-1,912, 1989.

Fei, Y., and H. K. Mao, In situ determination of the NiAs phase of $\mathrm{FeO}$ at high pressure and temperature, Science, 266, 1678-1680, 1994.

Forte, A. M. and W. R. Peltier, Core-mantle boundary topography and whole-mantle convection, Geophys. Res. Lett., 16, 621-624, 1989.

Funamori, N., and T. Yagi, High pressure and high temperature in situ X-ray observation of $\mathrm{MgSiO}_{3}$ perovskite under lower mantle conditions, Geophys. Res. Lett., 20, 387-390, 1993.

Gaffney, E. S., and D. L. Anderson, Effect of low-spin $\mathrm{Fe}^{2+}$ on the composition of the lower mantle, J. Geophys. Res., 78, 7,005-7,014, 1973.

Gaherty, J. B., and B. H. Hager, Compositional vs. thermal buoyancy and the evolution of subducted lithosphere, Geophys. Res. Lett., 21, 141-144, 1994.

Garnero, E. J., and D. V. Helmberger, A very slow basal layer underlying large-scale low-velocity anomalies in the lower mantle beneath the Pacific: evidence from core phases, Phys. Earth Planet. Inter., 91, 161-176, 1995.

Garnero, E. J., and D. V. Helmberger, Seismic detection of a thin laterally varying boundary layer at the base of the mantle beneath the central-Pacific, Geophys. Res. Lett., 23, 977-980, 1996.

Grand, S. P., Mantle shear structure beneath the Americas and surrounding oceans, J. Geophys. Res., 99, 11,59111,622, 1994.

Grand, S. P., R. D. van der Hilst, and S. Widiyantoro, Global seismic tomography: a snapshot of convection in the Earth, GSA Today, 7, 1-7, 1997.

Gurnis, M., The effects of chemical density differences on convective mixing in the Earth's mantle, J. Geophys. Res., $91,11,407-11,419,1986$.

Gurnis, M. and G. F. Davies, Mixing in numerical models of mantle convection incorporating plate kinematics, $J$. Geophys. Res., 91, 6,375-6,395, 1986.

Hager, B. H., R. W. Clayton, M. A. Richards, R. P. Comer, and A. M. Dziewonski, Lower mantle heterogeneity, dy- namic topography and the geoid, Nature, 313, 541-545, 1985.

Hansen, U., and D. A. Yuen, Dynamical influences from thermal-chemical instabilities at the core-mantle boundary, Geophys. Res. Lett., 16, 629-632, 1989.

Hemley, R. J., L. Stixrude, Y. Fei, and H. K. Mao, 1992. Constraints on lower mantle composition from $P-V-T$ measurements of $(\mathrm{Fe}, \mathrm{Mg}) \mathrm{SiO}_{3}$-perovskite and $(\mathrm{Fe}, \mathrm{Mg}) \mathrm{O}$. In: $Y$. Syono and M H. Manghnani (Editors), Highpressure research: Application to Earth and Planetary Sciences, American Geophysical Union, Washington, DC, pp. 183-189.

Isaak, D. G., The mixed $P, T$ derivatives of elastic moduli and implications on extrapolating throughout Earth's mantle, Phys. Earth Planet. Inter., 80, 37-48, 1993.

Isaak, D. G., O. L. Anderson, and T. Goto, Measured elastic moduli of single-crystal $\mathrm{MgO}$ up to $1800 \mathrm{~K}$, Phys. Chem. Minerals, 16, 704-713, 1989.

Isaak, D. G., R. E. Cohen, and M. J. Mehl, Calculated elastic and thermal properties of $\mathrm{MgO}$ at high pressures and temperatures, J. Geophys. Res., 95, 7,055-7,067, 1990.

Isaak, D. G, O. L. Anderson, and R. E. Cohen, The relationship between shear and compressional velocities at high pressures: Reconciliation of seismic tomography and mineral physics, Geophys. Res. Lett., 19, 741-744, 1992.

Jackson, I., and S. M. Rigden, Analysis of $P-V-T$ data: Constraints on the thermoelastic properties of highpressure minerals, Phys. Earth Planet. Inter., 96, 85-112, 1996.

Jackson, I., and A. E. Ringwood, High-pressure polymorphism of the iron oxides, Geophys. J. R. Astron. Soc., 64, 767-783, 1981.

Jeanloz, R., Phase transitions in the mantle, Nature, 340, 184, 1989.

Jeanloz, R., and T. J. Ahrens, Equations of state of $\mathrm{FeO}$ and $\mathrm{CaO}$, Geophys. J. R. Astron. Soc., 62, 505-528, 1980.

Jeanloz, R., and E. Knittle, 1986. Reduction of mantle and core properties to a standard state by adiabatic decompression. In: S. K. Saxena (Editor), Chemistry and physics of terrestrial planets. Springer, New York, pp. 275309.

Karki, B. B., M. C. Warren, L. Stixrude, G. J. Ackland, and J. Crain, $A b$ initio studies of high-pressure structural transformations in silica, Phys. Rev. B, 55, 3,465-3,471, 1997a.

Karki, B. B., M. C. Warren, L. Stixrude, G. J. Ackland, and J. Crain, $A b$ initio studies of high-pressure structural transformations in silica, Phys. Rev. B, 56, 2,884-2,884, 1997b.

Kellogg, L. H., and S. D. King, Effect of mantle plumes on the growth of D" by reaction between the core and mantle, Geophys. Res. Lett., 20, 379-382, 1993.

Kendall, J.-M., and P. M. Shearer, Lateral variations in D" thickness from long-period shear wave data, J. Geophys. Res., 99, 11,575-11,590, 1994.

Kesson, S. E. and J. D. Fitz Gerald, Partitioning of $\mathrm{MgO}$, $\mathrm{FeO}, \mathrm{NiO}, \mathrm{MnO}$ and $\mathrm{Cr}_{2} \mathrm{O}_{3}$ between magnesian silicate perovskite and magnesiowüstite: implications for the origin of inclusions in diamond and the composition of the lower mantle, Earth Planet. Sci. Lett., 111, 229-240, 1992. King, S. D., A. Raefsky, and B. H. Hager, ConMan: Vec- 
torizing a finite element code for incompressible twodimensional convection in the Earth's mantle, Phys. Earth Planet. Inter., 59, 195-207, 1990.

Kingma, K. J., R. E. Cohen, R. J. Hemley, and H.K. Mao, Transformation of stishovite to a denser phase at lowermantle pressures, Nature, 374, 243-245, 1995.

Knittle, E. and R. Jeanloz, High-pressure metallization of $\mathrm{FeO}$ and implications for the Earth's core, Geophys. Res. Lett., 13, 1,541-1,544, 1986.

Knittle, E. and R. Jeanloz, Earth's core-mantle boundary: Results of experiments at high pressures and temperatures, Science, 251, 1,438-1,443, 1991.

Knittle, E., R. Jeanloz, and G. L. Smith, Thermal expansion of silicate perovskite and stratification of the Earth's mantle, Nature, 319, 214-216, 1986.

Lay, T., and D. V. Helmberger, A lower mantle $S$ wave triplication and the shear velocity structure of D", Geophys. J. R. Astron. Soc., 75, 799-838, 1983.

Lenardic, A., and W. M. Kaula, Tectonic plates, D" structure, and the nature of mantle plumes, J. Geophys. Res., 99, 15,697-15,708, 1994.

Li, B., S. M. Rigden, and R. C. Liebermann, Elasticity of stishovite at high pressure, Phys. Earth Planet. Inter., 96, 113-127, 1996.

Loper, D. E., and T. Lay, The core-mantle boundary region, J. Geophys. Res., 100, 6,397-6,420, 1995.

Mao, H. K., R. J. Hemley, Y. Fei, J. Shu, L. Chen, A. P. Jephcoat, W. Wu, and W. A. Basset, Effect of pressure, temperature, and composition on lattice parameters and density of (Fe, $\mathrm{Mg}$ ) $\mathrm{SiO}_{3}$-perovskites to $30 \mathrm{GPa}, J$. Geophys. Res., 96, 8,069-8,079, 1991.

Meade, C., H. K. Mao, and J. Hu, High temperature phase transition and dissociation of $(\mathrm{Mg}, \mathrm{Fe}) \mathrm{SiO}_{3}$ perovskite at lower mantle pressures, Science, 268, 1,743-1,745, 1995.

Mitrovica, J.X., and A.M. Forte, Radial profile of mantle viscosity: Results from the joint inversion of convection and postglacial rebound observables, J. Geophys. Res., 102, 2,751-2,769, 1997.

Nataf, H-C., and S. Houard, Seismic discontinuity at the top of D": A world-wide feature?, Geophys. Res. Lett., 20, 2,371-2,374, 1993.

Olson, P., and C. Kincaid, Experiments on the interaction of thermal convection and compositional layering at the base of the mantle, J. Geophys. Res., 96, 4,347-4,354, 1991.

Patel, A., G. D. Price, M. Matsui, J. Brodholt, and R. Howarth, A computer simulation approach to the high pressure thermoelasticity of $\mathrm{MgSiO}_{3}$ perovskite, Phys. Earth Planet. Inter., 98, 55-63, 1996.

Richards, M. A., and G. F. Davies, On the separation of relatively buoyant components from subducted lithosphere, Geophys. Res. Lett., 16, 831-834, 1989.

Ruff, L., and D. L. Anderson, Core formation, evolution, and convection: A geophysical model, Phys. Earth Planet. Inter., 21, 181-201, 1980.

Sammis, C., D. L. Anderson, and T. Jordan, Application of isotropic finite strain theory to ultrasonic and seismological data, J. Geophys. Res., 75, 4,478-4,480, 1970.

Saxena, S. K., Earth mineralogical model: Gibbs free energy minimization computation in the system $\mathrm{MgO}-\mathrm{FeO}-\mathrm{SiO}_{2}$, Geochim. Cosmochim. Acta, 60, 2,379-2,395, 1996.

Sherman, D. M., High-spin to low-spin transition of iron(II) oxides at high pressures: Possible effects on the physics and chemistry of the lower mantle. In: S. Ghose et al. (Editors), Structural and Magnetic Phase Transitions in Minerals, Adv. Phys. Geochem., 7, 113-128, 1988.

Sherman, D. M., and H. J. F. Jansen, First-principles prediction of the high-pressure phase transition and electronic structure of FeO: Implications for the chemistry of the lower mantle and core, Geophys. Res. Lett., 22, 1,0011,004, 1995.

Sleep, N. H., Gradual entrainment of a chemical layer at the base of the mantle by overlying convection, Geophys. J. Int., 95, 437-447, 1988.

Stacey, F. D., Thermoelasticity of $(\mathrm{Mg}, \mathrm{Fe}) \mathrm{SiO}_{3}$ perovskite and a comparison with the lower mantle, Phys. Earth Planet. Inter., 98, 65-77, 1996.

Stixrude, L., and M. S. T. Bukowinski, Fundamental thermodynamic relations and silicate melting with implications for the constitution of D", J. Geophys. Res., 95, 19,311-19,325, 1990.

Stixrude, L., and R. E. Cohen, Stability of orthorhombic $\mathrm{MgSiO}_{3}$ perovskite in the Earth's lower mantle, Nature, 364, 613-615, 1993.

Stixrude, L., R. J. Hemley, Y. Fei, and H. K. Mao, Thermoelasticity of silicate perovskite and magnesiowüstite and stratification of the Earth's mantle, Science, 257, 1,099$1,101,1992$.

Strens, R. G. J., The nature and geophysical importance of spin-pairing in minerals of iron (II). In: S. K. Runcorn (Editor), The Physics and Chemistry of Minerals and Rocks, John Wiley, New York, pp. 213-220, 1969.

Suzuki, I., Thermal expansion of periclase and olivine, and their anharmonic properties, J. Phys. Earth, 23, 145-159, 1975.

Suzuki, I., S. Okajima, and K. Seya, Thermal expansion of single-crystal manganosite, J. Phys. Earth, 27, 63-69, 1979.

Tackley, P., Three-dimensional simulations of mantle convection with a thermochemical CMB boundary layer: D"?, this volume, 1998.

Tsuchida, Y., and T. Yagi, A new, post-stishovite highpressure polymorph of silica, Nature, 340, 217-220, 1989.

Utsumi, W., N. Funamori, T. Yagi, E. Ito, T. Kikegawa, and $\mathrm{O}$. Shimomura, Thermal expansivity of $\mathrm{MgSiO}_{3}$ perovskite under high pressures up to $20 \mathrm{GPa}$, Geophys. Res. Lett., 22, 1,005-1,008, 1995.

van der Hilst, R. D., S. Widiyantoro, and E. R. Engdahl, Evidence for deep mantle circulation from global tomography, Nature, 386, 578-584, 1997.

van Keken, P.E., S.D. King, H. Schmeling, U.R. Christensen, D. Neumeister, and M.-P. Doin, A comparison of methods for the modeling of thermochemical convection, J. Geophys. Res., 102, 22,477-22,495, 1997.

Vassiliou, M. S., and T. J. Ahrens, The equation of state of $\mathrm{Mg}_{0.6} \mathrm{Fe}_{0.4} \mathrm{O}$ to $200 \mathrm{GPa}$, Geophys. Res. Lett., 9, 127-130, 1982.

Vidale, J. E., and H. M. Benz, Seismological mapping of fine structure near the base of the Earth's mantle, Nature, 361, 529-532, 1993.

Wang, Y., D. J. Weidner, R. C. Liebermann, and Y. Zhao, $P-V-T$ equation of state of $(\mathrm{Mg}, \mathrm{Fe}) \mathrm{SiO}_{3}$ perovskite: constraints on composition of the lower mantle, Phys. Earth Planet. Inter., 83, 13-40, 1994.

Watt, J. P., G. F. Davies, and R. J. O'Connell, The elastic 
properties of composite materials, Rev. Geophys. Space Phys., 14, 541-563, 1976.

Williams, Q., The temperature contrast across D", this volume, 1998.

Williams, Q., and E. J. Garnero, Seismic evidence for partial melt at the base of Earth's mantle, Science, 273, 1,5281,530, 1996.

Wysession, M. E., 1996. Imaging cold rock at the base of the mantle: The sometimes fate of slabs? In: Subduction: Top to Bottom, Geophysical Monograph 96, AGU, Washington, DC, pp. 369-384.

Yagi, T., T. Suzuki, and S. Akimoto, Static compression of wüstite $\left(\mathrm{Fe}_{0.98} \mathrm{O}\right)$ to $120 \mathrm{GPa}, J$. Geophys. Res., 90, 8,784-8,788, 1985.

Yagi, T., K. Fukuoka, H. Takei, and Y. Syono, Shock compression of wüstite, Geophys. Res. Lett., 15, 816-819, 1988.

Yamamoto, S., I. Ohno, and O. L. Anderson, High temperature elasticity of sodium chloride, J. Phys. Chem. Solids, 48, 143-151, 1987.

Yeganeh-Haeri, A., Synthesis and re-investigation of the elastic properties of single-crystal magnesium silicate perovskite, Phys. Earth Planet. Inter., 87, 111-121, 1994.

Yuen, D. A., O. Cadek, A. Chopelas, and C. Matyska, Geo- physical inferences of thermal-chemical structures in the lower mantle, Geophys. Res. Lett., 20, 899-902, 1993.

Yuen, D. A., A. M. Leitch, and U. Hansen, 1991. Dynamical influences of pressure-dependent thermal expansivity on mantle convection. In: R. Sabadini and K. Lambeck (Editors), Glacial Isostasy, Sea-level and Mantle Rheology, Kluwer, Dordrecht, pp. 663-701.

Zhao, Y., and D. L. Anderson, Mineral physics constraints on the chemical composition of the Earth's lower mantle, Phys. Earth Planet. Inter., 85, 273-202, 1994.

Zhong, S., and M. Gurnis, Dynamic feedback between a continentlike raft and thermal convection, J. Geophys. Res., 98, 12,219-12,232, 1993.

Zhong, S., and M. Gurnis, Mantle convection with plates and mobile, faulted plate margins, Science, 267, 838-843, 1995.

Zou, G. T., H. K. Mao, P. M. Bell, and D. Virgo, Highpressure experiments on the iron oxide wüstite $\left(\mathrm{Fe}_{1-x} \mathrm{O}\right)$, Year Book Carnegie Inst. Washington, 79, 374-376, 1980.

Igor Sidorin and Michael Gurnis, Seismological Laboratory

252-21, California Institute of Technology, Pasadena, CA 91125. (e-mail: igor@gps.caltech.edu; gurnis@caltech.edu) 